\title{
Thermochemical compatibilization of reclaimed tire rubber/ poly(ethylene-co-vinyl acetate) blend using electron beam irradiation and amine-based chemical
}

\author{
Suganti Ramarad ${ }^{1}(1) \cdot$ Chantara Thevy Ratnam ${ }^{2} \cdot$ Yamuna Munusamy $^{3} \cdot$ Nor Azura Abdul Rahim $^{4}$. \\ Mathialagan Muniyadi ${ }^{3}$
}

Received: 30 March 2021 / Accepted: 6 September 2021 / Published online: 20 September 2021

(C) The Author(s) 2021

\begin{abstract}
Waste tire rubber is commonly recycled by blending with other polymers. However, the mechanical properties of these blends were poor due to lack of adhesion between the matrix and the waste tire rubber. In this research, the use of electron beam irradiation and (3-Aminopropyl)triethoxy silane (APTES) on enhancing the performance of $50 \mathrm{wt} \%$ reclaimed tire rubber (RTR) blend with $50 \mathrm{wt} \%$ poly(ethylene-co-vinyl acetate) (EVA) was investigated. Preparation of RTR/EVA blends were carried out in the internal mixer. The blends were then exposed to electron beam (EB) irradiation at doses ranging from 50 to $200 \mathrm{kGy}$. APTES loading was varied between 1 to $10 \mathrm{wt} \%$. The processing, morphological, mechanical, and calorimetric properties of the blends were investigated. The stabilization torque and total mixing energy was higher in compatibilized blends. Mechanical properties of RTR/EVA blends were improved due to efficiency of APTES in further reclaiming the RTR and compatibilizing the blends. APTES improved the dispersion of embedded smaller RTR particles in EVA matrix and crosslinking efficiency of the blends. Calorimetric studies showed increased crystallinity in compatibilized blends which corresponds to improved mechanical properties. However, the ductility of the blend was decreased due to increased interaction between EVA and APTES. Presence of APTES increased the efficiency of electron beam irradiation induced crosslinking which was shown through gel content analysis and Charlesby-Pinner equation.
\end{abstract}

Keywords Recycling $\cdot$ Reclaimed waste tire rubber $\cdot$ Ethylene vinyl acetate $\cdot$ Interphase $\cdot$ Silane coupling agent

\section{Introduction}

Tires can be accounted as one of the toughest polymeric material to be recycled. Tires have been designed with complex structure to enable good mechanical properties which ensure safety and durability during service life [1]. However, these complex structure and excellent mechanical properties render the tires non-degradable and painstaking to recycle after life on the road [2]. The main constituent of a tire is rubber and carbon black fillers, which are common materials used in polymeric composites [3, 4]. At disposal, a tire is still found to have $67 \%$ of functional valuable materials. This further strengthens the urge to recycle waste tires.

Suganti Ramarad

R.Suganti@hw.ac.uk

Extended author information available on the last page of the article
Bulky waste tires are shredded, pulverized or granulated to obtain waste rubber powder which is then incorporated into polymeric materials as a mean to recycle it [5]. This powder is also commonly known as ground tire rubber (GTR). GTR have been infamously incorporated into thermoplastic matrix but has not found much success due to distinct loss of matrix ductility and toughness[6]. Thus, reclaiming method was developed and used on crosslinked rubber to partially devulcanize the rubber to increase the plasticity and processability of the rubber [5]. Reclaimed tire rubber (RTR) happens to be the second most commonly used type of waste tire rubber in the polymer industry.

Weak interfacial adhesion between the polymer and GTR is reported as one of the factors contributing to loss of ductility and toughness in GTR/thermoplastic compound [7-9]. Very few studies reported on successful methods in improving the interfacial properties of GTR/ thermoplastic compounds [10-14]. RTR is likely to exhibit 
improved interfacial properties compared to GTR, owing to the partially devulcanized RTR surface which enables enhanced interaction between the thermoplastic and RTR. However, it still is important to further enhance the interfacial properties of the RTR to produce blends with superior performance. In this study, (3-Aminopropyl)triethoxy silane (APTES) has been employed as compatibilizer for RTR/EVA blends, via reactive compatibilization method.

High energy ionizing radiations such as electron beam and gamma irradiation have been actively used to enhance the properties of polymeric materials. This is due to the ability of ionizing radiation to crosslink, degrade, graft or cure polymeric materials upon exposure to irradiation [15]. Properties enhancement and improved compatibilization in the blends of recycled materials such as GTR subjected to the use of high energy radiation have been reported previously. Studies on gamma irradiation of GTR/polyethylene [16] and electron beam irradiation of GTR/EVA [17] showed improved interfacial adhesion between GTR particles and the enveloping thermoplastic matrix due to the ionizing radiation. This study explored the feasibility of using electron beam irradiation to enhance the properties of APTES compatibilized RTR/EVA blends.

\section{Materials and methods}

\section{Materials}

Poly(ethylene-co-vinyl acetate) (EVA) Grade EVA N8045 was supplied by TPI POLENA Public Limited Company, Thailand. EVA N8045 contains 18\% vinyl acetate, with a melt flow index (MFI) value of, $2.3 \mathrm{~g} / 10 \mathrm{~min}$ and a density
Table 1 Blend formulation

\begin{tabular}{llll}
\hline Designation & RTR (wt\%) & EVA (wt\%) & $\begin{array}{l}\text { APTES }^{\mathrm{a}} \\
(\mathrm{wt} \%)\end{array}$ \\
\hline RTR & 100 & 0 & \\
50RTR & 50 & 50 & \\
EVA & 0 & 100 & $1,3,5 \& 10$ \\
5ORTR/XAPTES & 50 & 50 &
\end{tabular}

${ }^{a} \mathrm{wt} \%$ of APTES added based on total weight of RTR

${ }^{\mathbf{b}} \mathrm{X}$ indicates the wt\% of APTES loading

of $0.947 \mathrm{~g} / \mathrm{cm}^{3}$. Reclaimed tire rubber, RTR, with grade RECLAIM Rubberplas C, was supplied by Rubplast Sdn. Bhd., Malaysia. RTR was derived from waste heavy duty tires. The RTR contains $48 \%$ rubber hydrocarbon, $25 \%$ carbon black fillers, $15 \%$ acetone extract, $5 \%$ ash content with a density of $1.3 \mathrm{~g} / \mathrm{cm}^{3}$. (3-Aminopropyl)triethoxy silane (APTES) supplied by Sigma Aldrich was used as compatibilizer in RTR/EVA blends. APTES had specific gravity of $0.95 \mathrm{~g} / \mathrm{cm}^{3}$ and boiling point of $217^{\circ} \mathrm{C}$.

\section{Melt blending of RTR/EVA}

An internal mixer model Brabender Plasticoder PL2000-6, supplied by Brabender GmbH \& Co. company was used to melt blend the RTR and EVA. A schematic of the internal mixer is shown in Fig. 1. The blending temperature and rotor speed was fixed to $120^{\circ} \mathrm{C}$ and $50 \mathrm{rpm}$, respectively. RTR to EVA blending ration was fixed at 50:50 for all the blends. EVA was discharged first into the mixing
Fig. 1 Schematic representation of a corotating twin screw blade equipped internal mixer

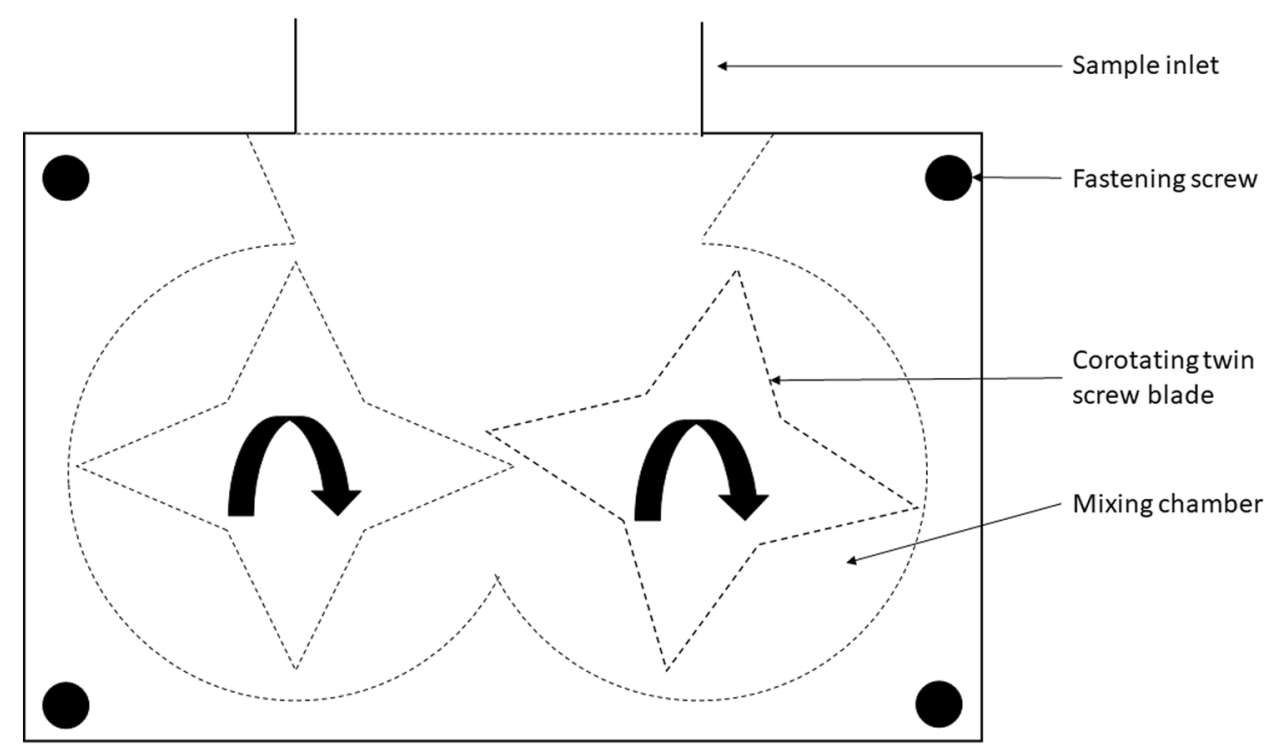


chamber, followed by addition of RTR and APTES after $2 \mathrm{~min}$. All the prepared blends were subjected to the total mixing time of $10 \mathrm{~min}$ and the torque reading during mixing was recorded. The melt mixed blends were collected, and compression moulded. Table 1 shows the formulation of the prepared blends.

Blends collected after melt mixing were compression moulded to form appropriate test pieces. The blends were separately moulded into sheets with the thickness of 1, 2 and $5 \mathrm{~mm}$ at $130{ }^{\circ} \mathrm{C}$. Each moulding cycle included $3 \mathrm{~min}$ of pressure-less preheating, venting for $20 \mathrm{~s}$ and then followed by compression under pressure of $14.7 \mathrm{MPa}$ for $3 \mathrm{~min}$ using LP-S-50 Scientific Hot and Cold Press supplied by LabTech Engineering Company Ltd. The hot-pressed sheets were directly cooled at $20{ }^{\circ} \mathrm{C}$ for $2 \mathrm{~min}$ in a cold press equipped with a chiller.

\section{Electron beam irradiation}

The compression moulded sheets were irradiated using the $3 \mathrm{MeV}$ electron beam accelerator (model NHV-EPS-3000) at doses ranging between $0-200 \mathrm{kGy}$. The acceleration energy, beam current and dose rate were $2 \mathrm{MeV}, 5 \mathrm{~mA}$, and $50 \mathrm{kGy}$ per pass, respectively.

\section{Physical and mechanical characterization}

Gel content of the samples was determined using ASTM D2765 method. Each irradiated sheet was cut into small pieces with approximately $0.5 \mathrm{~g}$ weight and inserted into a stainless steel wire mesh sample pouch of 120 mesh size. The samples were soaked into toluene and extracted through boiling the toulene for $24 \mathrm{~h}$ using Soxhlet apparatus. After extraction, the samples were dried in an oven at $70{ }^{\circ} \mathrm{C}$ until a constant weight was obtained. The gel content was calculated as per Eq. 1.

Gel content $=\frac{\mathrm{W}_{1}}{\mathrm{~W}_{0}} \times 100$

where $\mathrm{W}_{0}$ and $\mathrm{W}_{1}$ are the dried weight of sample before extraction and after extraction, respectively.

Ratio of chain scission to crosslinking $\left(\mathrm{p}_{0} / \mathrm{q}_{0}\right)$ in the blend upon exposure to irradiation were obtained quantitatively from plots of $S+S^{1 / 2}$ versus 1/D based on Charlesby-Pinner equation, Eq. 2.

$S+S^{1 / 2}=\frac{p_{0}}{q_{0}}+\frac{10}{q_{0} D u_{1}}$

where $\mathrm{S}$ is the sol fraction, $\mathrm{u}_{1}$ the number averaged degree of polymerization, $\mathrm{D}$ is radiation dose (in $\mathrm{kGy}$ ), $\mathrm{p}_{0}$ and $\mathrm{q}_{0}$ are fraction of ruptured and crosslinked main-chain units per unit dose, respectively. RTR contained a substantial amount of gel before irradiation, hence, the sol fraction used in this study was derived from the absolute yield of gel fraction upon irradiation (gel content after irradiation minus gel content before irradiation).

Gel permeation chromatography (GPC) characterization was done for a couple of RTR samples to determine the molar mass distribution of the soluble rubber fraction. Firstly, low molecular weight moieties/additives in RTR samples were removed through $24 \mathrm{~h}$ boiling acetone extraction in Soxhlet apparatus. Then the RTR samples were washed with toluene and extracted again for $24 \mathrm{~h}$ in boiling toluene to further remove the soluble fraction of RTR. Filter paper was used to separate the non-dissolving RTR components and toluene. Soluble rubber fraction of RTR was obtained by evaporating the Toluene by drying in the oven at $50{ }^{\circ} \mathrm{C}$ for $6 \mathrm{~h}$. GPC evaluation was done on the dried soluble rubber by dissolving the soluble rubber in tetrahydrofuran (THF). The solute was passed through a column packed with porous materials that separates polymer chains based on molecule size. The GPC test were done according to polystyrene standard.

Tensile test was carried out in accordance to ASTM D412 standard using dumbbell shaped specimens with $25 \mathrm{~mm}$ gauge length, $6 \mathrm{~mm}$ width and $1 \mathrm{~mm}$ thickness. Wallace die cutter was used to punch out the tensile test specimens from the compression moulded sheets. The test was done at room temperature using Toyoseiki universal testing machine supplied by Toyo Seiki Seisaku-sho, Ltd. Japan; equipped with $10 \mathrm{kN}$ load cell. All samples were pulled under tension at crosshead speed of $50 \mathrm{~mm} / \mathrm{min}$. Tensile strength, modulus at $100 \%$ elongation and elongation at break were recorded. A minimum of 7 specimens were used for each set of blends and the average results were taken as the resultant value.

Tear testing was conducted as per ASTM D264 standard. Test specimens with $102 \mathrm{~mm}$ length, $10 \mathrm{~mm}$ width and $1.5 \mathrm{~mm}$ thickness were cut manually using a sharp blade from the compression moulded sheets according to ASTM D624 Type C (right angle) test piece specification. The tear test was carried out at room temperature with Toyoseiki universal testing machine, supplied by Toyo Seiki Seisaku-sho, Ltd. Japan; equipped with $10 \mathrm{kN}$ load cell. All samples were tested at the crosshead speed of $50 \mathrm{~mm} /$ min. Six specimens were used for each set of blends and the average tear strength results were taken.

Hardness test was conducted according to ASTM D2240 (Type Shore A) standard with samples directly produced from compression moulding with dimension of $100 \mathrm{~mm}$ length, $100 \mathrm{~mm}$ width and $5 \mathrm{~mm}$ thickness. The testing was carried out at room temperature with Durometer Hardness blunt indenter model Zwick 7206 supplied 
by Zwick Roell GmbH \& Co. A minimum of 9 hardness readings were recorded for each sample and the average results were taken as the resultant value.

\section{Morphological and thermal characterization}

The tensile fractured surfaces were observed with field emission scanning electron microscope (FESEM) Model FEI Quanta 400 supplied by Thermo Fisher Scientific to understand the nature of tensile failure. Firstly, the fractured surface samples were sputter coated with gold to avoid electrostatic charging and poor image resolution. Then the samples were stick to sample holder using carbon tape prior to imaging process.

The morphology of the blends was observed using transmission electron microscope (TEM) model Jeol-JEM-2100 supplied by JEOL Ltd, Japan. Ultrathin sections with approximate thickness of $80 \mathrm{~nm}$ were cut from the compression moulded sample sheets with ultra-microtome machine, model LEICA Ultracut UCT supplied by Leica Microsystem Ltd. at temperature of $-100{ }^{\circ} \mathrm{C}$ achieved using liquid nitrogen. The sections were placed on a carbon coated copper grid and observed under TEM using a voltage of $200 \mathrm{kV}$.

The crystallization and melting temperature, heat of fusion and degree of crystallinity of the blends were studied using differential scanning calorimeter (DSC), model Mettler Toledo DSC 1/32 equipped with STARe System supplied by Mettler Toledo. About 5 to $10 \mathrm{mg}$ of samples were analysed in $50 \mathrm{ml} / \mathrm{min}$ continuous flow of nitrogen gas. Firstly, the thermal history in the blends was erased by heating the samples from room temperature to $140{ }^{\circ} \mathrm{C}$ at $50{ }^{\circ} \mathrm{C} / \mathrm{min}$ followed by cooling to $0{ }^{\circ} \mathrm{C}$ at a cooling rate of $10{ }^{\circ} \mathrm{C} / \mathrm{min}$. Subsequently, second heating was done at a rate of $10{ }^{\circ} \mathrm{C} / \mathrm{min}$ up to $140{ }^{\circ} \mathrm{C}$ followed by cooling at a rate of $10^{\circ} \mathrm{C} / \mathrm{min}$ up to $0{ }^{\circ} \mathrm{C}$ to obtain melting temperature $(\mathrm{Tm})$, crystallization temperature $(\mathrm{Tc})$ and heat of fusion $\Delta \mathrm{H}_{\mathrm{f}}$. First heating scan was omitted from data analysis. The results were analysed using STARe System software. The percentage of crystallinity, $\mathrm{X}_{\mathrm{c}}$, of EVA in the blends was calculated as per Eq. 3 .

$\mathrm{X}_{\mathrm{c}}=\frac{\Delta \mathrm{H}_{\mathrm{f}}}{\Delta \mathrm{H}_{\mathrm{f}}^{\circ} \times \mathrm{w}_{\mathrm{EVA}}} \times 100$

where $\Delta \mathrm{H}_{\mathrm{f}}$ is the heat of fusion of the sample, $\Delta \mathrm{H}_{\mathrm{f}}{ }^{\circ}$ is the heat of fusion of a $100 \%$ crystalline polyethylene which is $295 \mathrm{~J} / \mathrm{g}$ and $\mathrm{w}_{\mathrm{EVA}}$ is the weight fraction of EVA in the blends.

Thermogravimetry analysis (TGA) experiment was used to determine the thermal stability of the samples using computerized thermo gravimetric analyzer (Mettler Toledo TGA/DSC 1 equipped with STARe System supplied by Mettler Toledo). Weight loss vs. temperature thermogram was obtained by heating the samples from room temperature to $600{ }^{\circ} \mathrm{C}$. All analysis was carried out using 5 to $10 \mathrm{mg}$ of samples in nitrogen atmosphere (flow rate $50 \mathrm{ml} / \mathrm{min}$ ) and a heating rate of $10^{\circ} \mathrm{C} / \mathrm{min}$. The results were analyzed using STARe System software. The normalized weight loss vs temperature curve was smoothed using a least-squares averaging technique before analysis.
Fig. 2 Trend of torque and time relationship for blends containing APTES

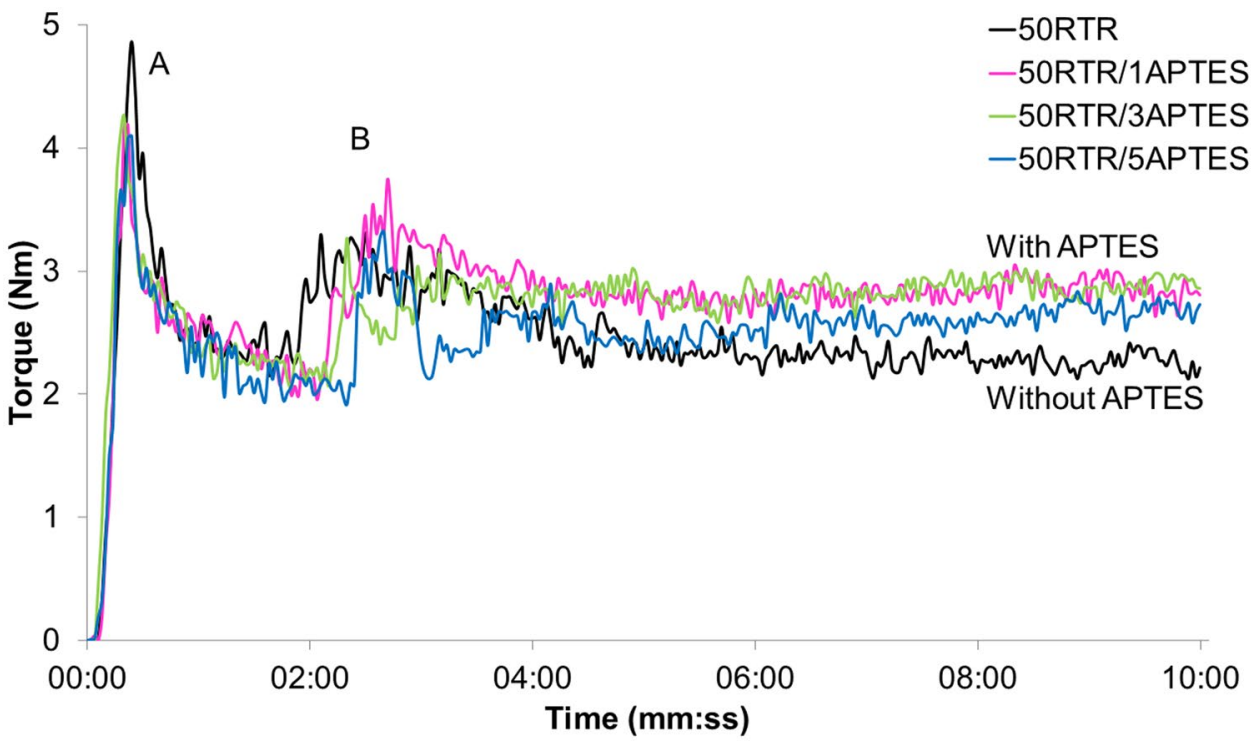




\section{Results and discussion}

\section{Processing characteristic}

The torque-time pattern of the APTES containing blends at different compatibilizer loading is shown in Fig. 2. The peaks of torque-time pattern at the twentieth second (peak A) and second minute (peak B) represents the introduction of EVA and RTR into the mixer, respectively. The torquetime pattern showed a stabilization plateau zone after $4 \mathrm{~min}$ till the end of mixing. Additionally, the absence of rising torque indicates the blends achieved homogenous mixing. All APTES containing blends showed similar torque-time pattern at EVA addition point (peak A) and complete melting of EVA. This is caused by the same loading of EVA used in entire formulated blends. However, RTR introduction torque (peak B) was decreasing with increasing APTES loading. APTES is in liquid form, providing lubricating effect and thereby reducing the torque reading with the increasing APTES loading. The recorded torque of APTES containing blends, at the end of the mixing, was higher than control blend, 50RTR. This could be due to increased interaction between EVA and RTR through compatibilization effect offered by APTES.

Figure 3 shows the influence of compatibilizer loading on torque readings during EVA loading, EVA melting, RTR loading and stabilization of the blends. The torque readings of introduction and melting of EVA in the APTES containing blends remained similar to 50RTR blend. This is also caused by the similar amount of EVA in all the blends. Conversely, RTR loading and stabilization torque readings are clearly affected by the presence of APTES. RTR loading torque of the blends decreased with increasing APTES
Table 2 Mixing energy of blends

\begin{tabular}{ll}
\hline Designation/loading & Energy $(\mathrm{kNm})$ \\
\hline 50RTR & $7.72 \pm 0.29$ \\
50RTR/1APTES & $8.16 \pm 0.45$ \\
50RTR/3APTES & $8.23 \pm 0.33$ \\
50RTR/5APTES & $8.23 \pm 0.34$ \\
\hline
\end{tabular}

loading. Apparently, this is caused by the reduction of viscosity as a result of APTES capability to further reclaim the RTR. More details on this mechanism will be discussed in the following sections. Increase in stabilization torque was noted with increasing APTES loading due to enhanced interaction between RTR and EVA from the efficient compatibilization by APTES, hence increasing the viscosity of the compatibilized blends.

In comparison to control blend, 50RTR, all APTES compatibilized blends recorded higher total mixing energy as shown in Table 2. The blends with 3 and 5 wt\% APTES loading recorded $8.23 \mathrm{kNm}$ total mixing energy which corresponds to $6.6 \%$ increase in total mixing energy compared to 50RTR. This is expected due to enhanced interaction between EVA and RTR resulting from efficiency of APTES as compatibilizer [18].

\section{Gel content analysis}

Figure 4 shows the function of the APTES loadings and irradiation doses on the gel content values of 50RTR blends. Interestingly, the gel content before irradiation $(0 \mathrm{kGy})$ of all APTES containing blends are lower than the control
Fig. 3 Specific torque values for blends containing APTES in comparison to 50RTR blend

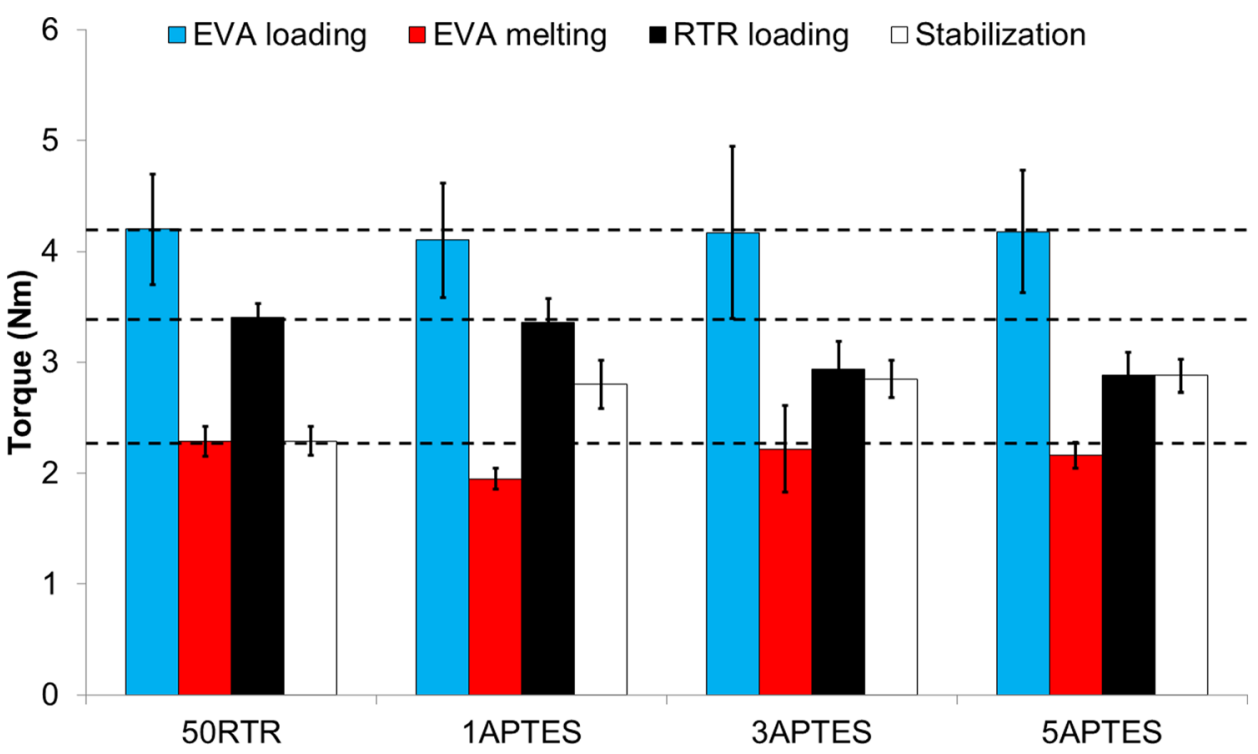


Fig. 4 Gel content of 50RTR blend as a function of irradiation dose and APTES loading

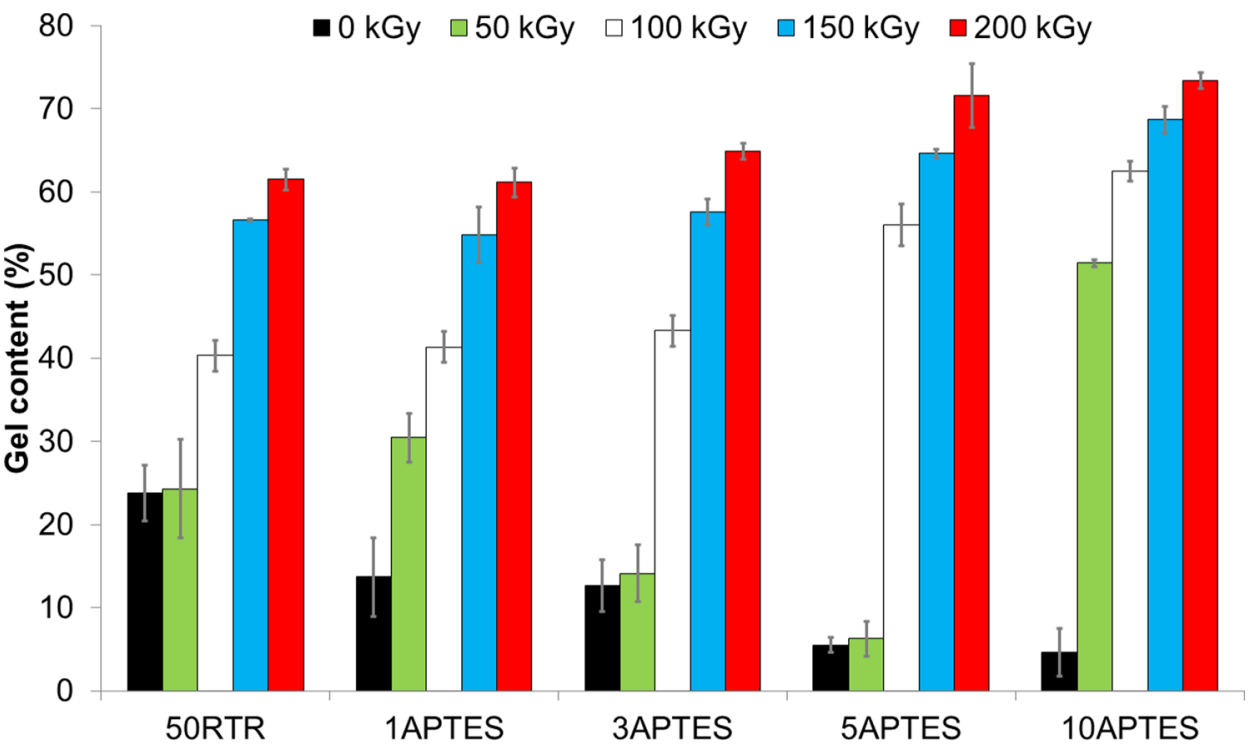

50RTR blend. The gel content of 50RTR blend at $0 \mathrm{kGy}$ was contributed by partially devulcanized structure of RTR [19]. Systematic reduction of gel content before irradiation with the increment of APTES loading in the blends was observed as a result of APTES capability to further devulcanize or reclaim the RTR. Amines were used as reclaiming agents since the introduction of rubber reclaiming by pan and digester process [20]. Amines were reported to function as reclaiming agents in rubber, where amines are capable of cleaving the crosslinks in vulcanized rubber via nucleophilic reaction. This is made possible by amines lone pair of electrons which display strong nucleophile nature.

Amines have been shown to successfully act as agents of reclaiming for EPDM rubber [21]. APTES can likewise function as a reclaiming agent for tire rubbers as it contains an aliphatic primary amine group. A mixture of 3 wt\% APTES with RTR (RTR/3APTES) was prepared in an internal mixer to evaluate the feasibility of APTES acting as reclaiming agent for RTR. Molar mass distribution of the soluble fraction of both RTR and RTR/3APTES was obtained through GPC evaluation, as shown in Table 3. Weight average molecular weight $\left(\mathrm{M}_{\mathrm{w})}\right.$, number average molecular weight $\left(\mathrm{M}_{\mathrm{n}}\right)$ and polydispersity index (PDI) of RTR decreased by $33 \%, 11 \%$ and $24.5 \%$, respectively with the addition of APTES. These evaluations validate that

Table $3 M_{w}, M_{n}$ and PDI of RTR and RTR with $3 w t \%$ APTES

\begin{tabular}{llll}
\hline & $\mathbf{M}_{\mathbf{w}}$ & $\mathbf{M}_{\mathbf{n}}$ & PDI \\
\hline RTR & 179,318 & 68,603 & 2.61 \\
RTR/3APTES & 119,809 & 60,798 & 1.97 \\
\hline
\end{tabular}

APTES plays an important role in the scissoring of crosslink networks in RTR.

50RTR blend showed a delay in crosslinking yield up to $50 \mathrm{kGy}$ irradiation dose following the readily present radical scavenging and stabilizing additive within RTR [19]. The efficiency of the yield of crosslinking, in APTES containing blends increases with increment of irradiation dose. The use of $10 \mathrm{wt} \%$ APTES completely resolved the delayed crosslinking yield observed in 50RTR. It is hypothesized that the APTES interacts with the additives in tire and residual radical scavenging reclaiming agents within RTR which enables the crosslinking process to take place in the blends. Compared to equivalent control, 50RTR blend; $5 \mathrm{wt} \%$ APTES containing blends showed improvement in gel content by $39 \%$ and $16 \%$ at $100 \mathrm{kGy}$ and $200 \mathrm{kGy}$ irradiation dose, respectively.

Table 4 shows the ratio of chain scission to crosslinking, $\mathrm{p}_{0} / \mathrm{q}_{0}$ values of the blends. The control blend, 50RTR, recorded a value of 1.27 for $\mathrm{p}_{0} / \mathrm{q}_{0}$ values, suggesting the prominence of chain scissions over crosslinking in this blend. Macroradicals formed during irradiation are stabilized or scavenged by additives such as stabilizers, fillers, antioxidants and residual reclaiming agent which are freely present in RTR. This reduces the likelihood of

Table 4 Ration of chain scission to crosslinking of 50RTR and APTES containing blends

\begin{tabular}{ll}
\hline Designation & $\mathrm{p}_{0} / \mathrm{q}_{0}$ \\
\hline 50RTR & 1.2669 \\
50RTR/1APTES & 1.1574 \\
50RTR/3APTES & 0.9411 \\
50RTR/5APTES & 0.5478 \\
50RTR/10APTES & 0.7853 \\
\hline
\end{tabular}




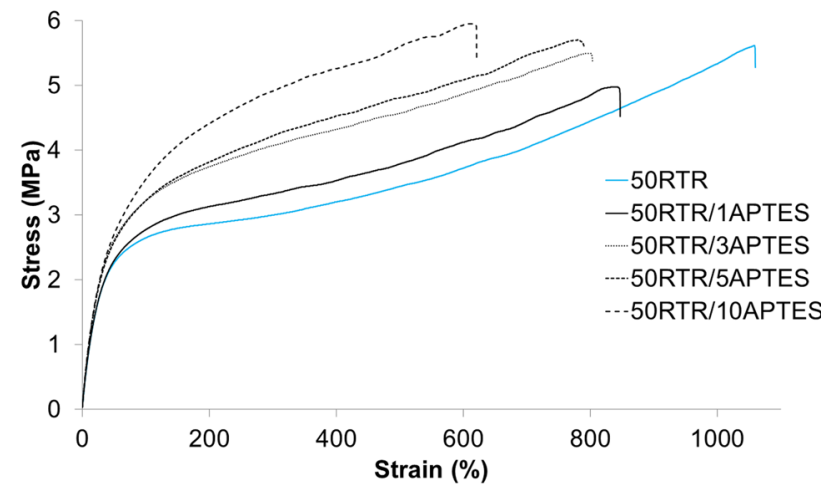

Fig. 5 Stress-strain curves of 50RTR and APTES containing blends before irradiation

macroradicals overlapping to form crosslinking, as well as increasing the possibilities of the polymeric chain scission [22]. The $\mathrm{p}_{0} / \mathrm{q}_{0}$ values decreases with the addition of APTES, suggesting improved crosslinking efficiency with the addition of APTES. At $5 \mathrm{wt} \%$ APTES loading, the $\mathrm{p}_{0} / \mathrm{q}_{0}$ value was reduced to half the control's (50RTR) $\mathrm{p}_{0} / \mathrm{q}_{0}$ value. This is due to combination effect of efficient reclaiming or devulcanization of RTR by APTES, and the interaction of APTES with radical scavenging additives readily present in the RTR. These effects increased the efficiency of radiation-induced crosslinking.

\section{Mechanical properties}

Figure 5 details the stress-strain behavior of compatibilized 50RTR blends at $0 \mathrm{kGy}$ irradiation (before irradiation). All the APTES containing blends show elastic deformation with
Table 5 Percentage of changes in tensile strength and EB of blends at $200 \mathrm{kGy}$ irradiation dose compared to non-irradiated blends

\begin{tabular}{lcc}
\hline Designation & Tensile strength $(\%)$ & EB $(\%)$ \\
\hline 50RTR & 15.69 & 12.96 \\
50RTR/1APTES & 25.40 & 1.83 \\
50RTR/3APTES & 18.69 & 0.30 \\
50RTR/5APTES & 6.71 & 11.58 \\
50RTR/10APTES & 5.06 & 11.38 \\
\hline
\end{tabular}

flexible and tough characteristic curve which occurred up to yield point. Following yield point, irreversible plastic deformation was noted till the point of fracture. Compatibilization of blends by APTES increases the blend strength at the loss of elongation at break.

The effects of irradiation doses and APTES loading on tensile strength of APTES containing 50RTR blends are presented in Fig. 6. In comparison to control blend, increase by $15.26 \%$ in tensile strength of $10 \mathrm{wt} \%$ APTES containing blends before irradiation $(0 \mathrm{kGy})$ was noted. Tensile strength increases before irradiation in APTES containing blends even though the gel content decreases due to effective interphase formation between RTR and EVA component in the presence of APTES. Materials could withstand higher amount of failure stress owing to the good interphase that promotes effective stress transfer [23] between RTR and EVA components.

Moreover, the use of APTES facilitated the dispersion of smaller sized rubber particles in the blends as evidenced from SEM micrographs in Fig. 14 which suggest an increment of effective surface area of interaction between EVA and RTR components. More elaborated discussion on these changes have been detailed in the morphological analysis section.
Fig. 6 Influence of APTES loading and irradiation dosage on tensile strength of 50RTR and APTES containing blends

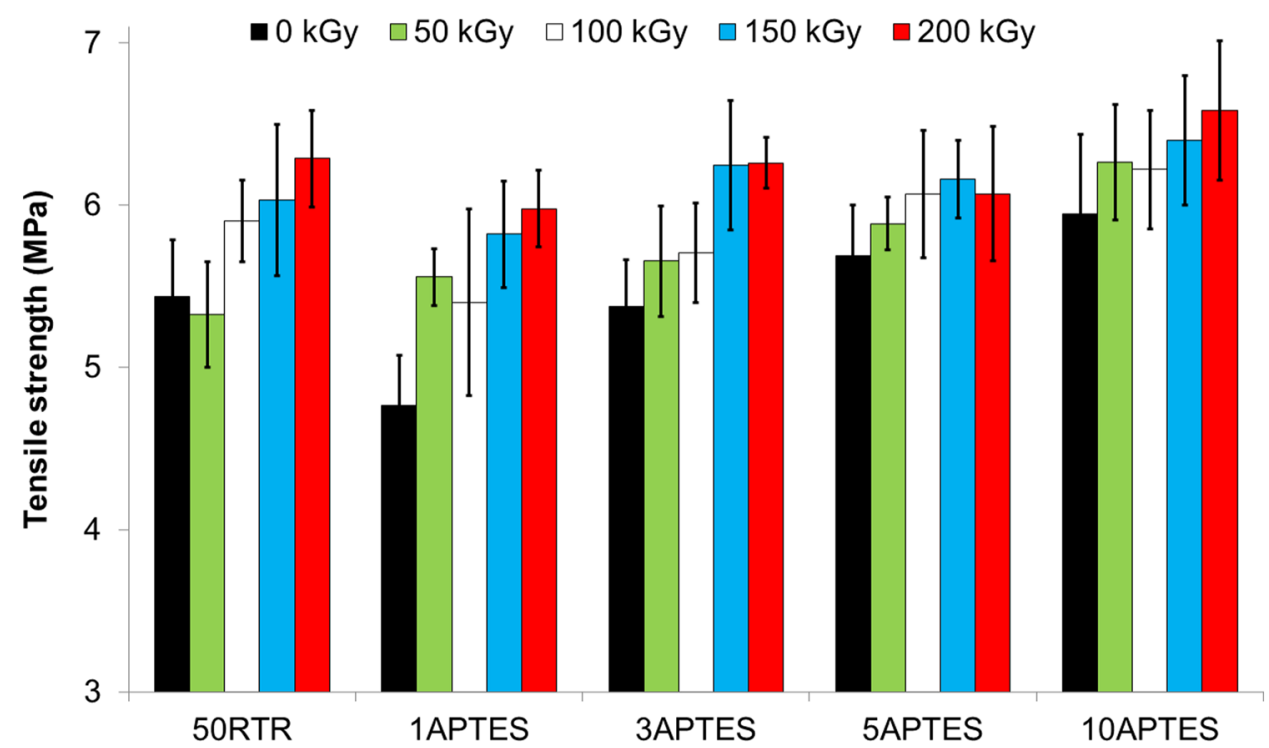


The effect of electron beam irradiation on the tensile properties of APTES containing blends can be inferred from Table 5 and Fig. 6. Tensile strength of APTES containing blends (at 1, 3, 5 \& $10 \mathrm{wt} \%$ loadings), showed an upward trend with increasing dose of irradiation. Nevertheless, Table 5 shows the effectiveness of irradiation induced enhancement in tensile strength of APTES containing blends decreases from $1 w t \%$ up until 5 wt $\%$ APTES loading and stabilizing thereafter. Efficiency of APTES as reclaiming agent of RTR causes considerable increase in tensile strength before irradiation. In addition, improvement in the gel content yield upon irradiation with increment of APTES loading was noted. These results suggest that higher loading of APTES in blends promotes formation of more irradiation induced crosslinks.

Figure 7 shows the effect of irradiation dose and APTES loading on EB of the blends. A drop of $42 \%$ in EB in 10 wt\% APTES containing blends was noted in comparison to 50RTR blends before irradiation. Values of EB before irradiation dropped systematically with increasing APTES loading. This observation might be caused by the improved adhesion between RTR and EVA resulting increased restriction of matrix to flow. However, a prominent decrease in EB was noticed with the addition of APTES. From previous study [19], it was apparent that EVA matrix mainly contributes to the EB of RTR/EVA blends. This suggest that EVA matrix properties could have been altered due to interaction between the amine group of APTES with the vinyl acetate group of EVA. To confirm this assumption, a mixture of 3 wt $\%$ APTES and EVA was prepared and tensile tested. The EVA/3APTES mixture showed a prominent $39 \%$ decrease in EB value in comparison to pure EVA. This indicates changes in the microstructure of EVA due to the chemical interaction between EVA and APTES, resulting in deterioration of EB.
In general, EB shows downward trend with the increment of irradiation dose [24] in APTES containing blends. Table 5 shows that at lower APTES loading ( 1 and $3 \mathrm{wt} \%)$ and in relation to increasing irradiation dose, no substantial changes was detected in percentage of changes in EB. Whereas, at 5 and $10 \mathrm{wt} \%$ APTES loading the decrease in percentage of changes of EB was similar to 50RTR. Higher amount of irradiation induced crosslinks was formed in the blends containing higher loading of APTES as suggested by the gel content analysis. At higher APTES loading, the prominent difference between gel content before and after irradiation, leads to a bigger difference in the EB of the blends. These observations are supported by Charlesby Pinner analysis whereby crosslinking is more dominant than chain-scission in APTES containing blends in comparison to 50RTR blend.

Figure 8 exhibit the effect of APTES loading and irradiation on modulus at $100 \%$ elongation (M100) of 50RTR blends. A 30\% increase in M100 was observed at $10 \mathrm{wt} \%$ APTES loading compared to control blend. As mentioned earlier, APTES functioned as reclaiming agent, breaking down the three-dimensional network system in RTR, which should have reduced the M100 value of the blend as the rubber is now softer. Nevertheless, an opposite trend was observed due to the domination of microstructural modification of EVA by interaction with APTES. Increase in the irradiation dose, increases the M100 values of APTES containing blends, suggesting increased stiffness caused by irradiation induced crosslinking [24, 25].

The influences of APTES loading and irradiation dose on the tear strength of 50RTR blends are shown in Fig. 9. Tear strength increased up to $5 \mathrm{wt} \%$ APTES loading and stabilized thereon. An improvement of $20 \%$ in tear strength of $5 \mathrm{wt} \%$ APTES blend at $0 \mathrm{kGy}$ was noted compared
Fig. 7 Influence of irradiation dosage and APTES loading on EB of 50RTR and APTES containing blends

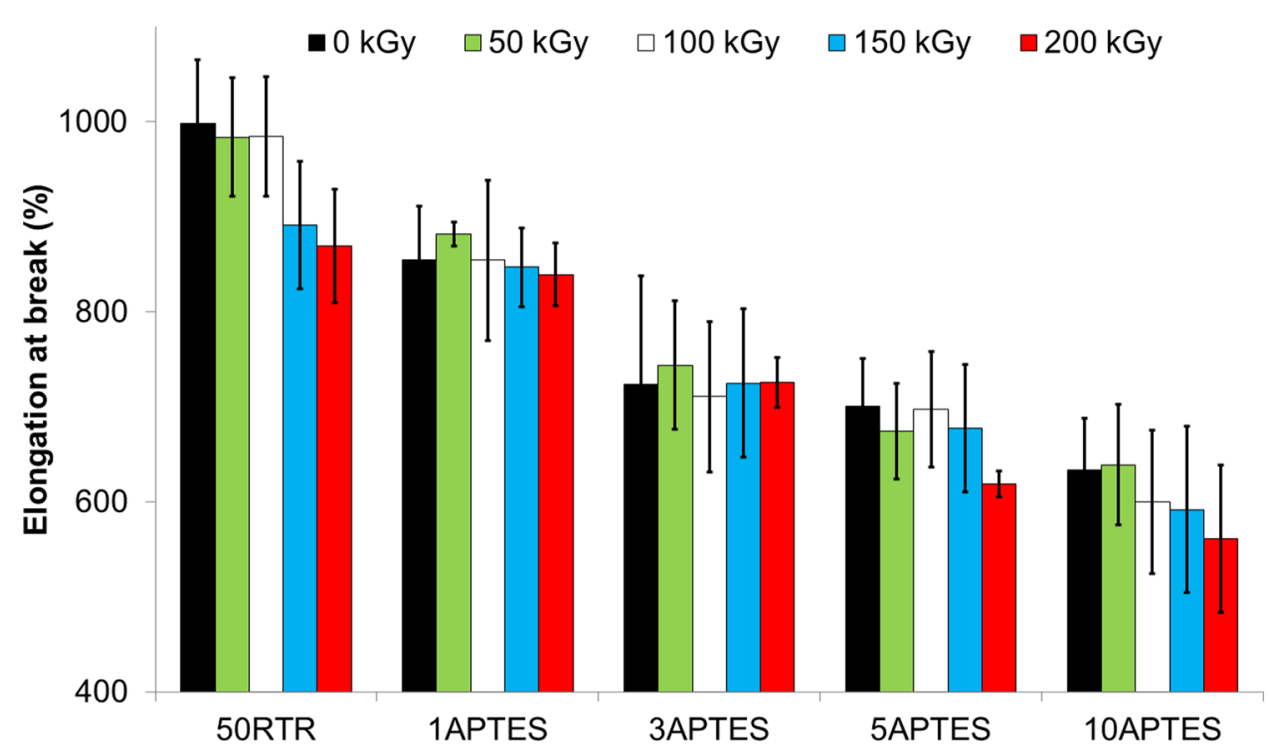


Fig. 8 Influence of irradiation dosage and APTES loading on M100 of 50RTR and APTES containing blends

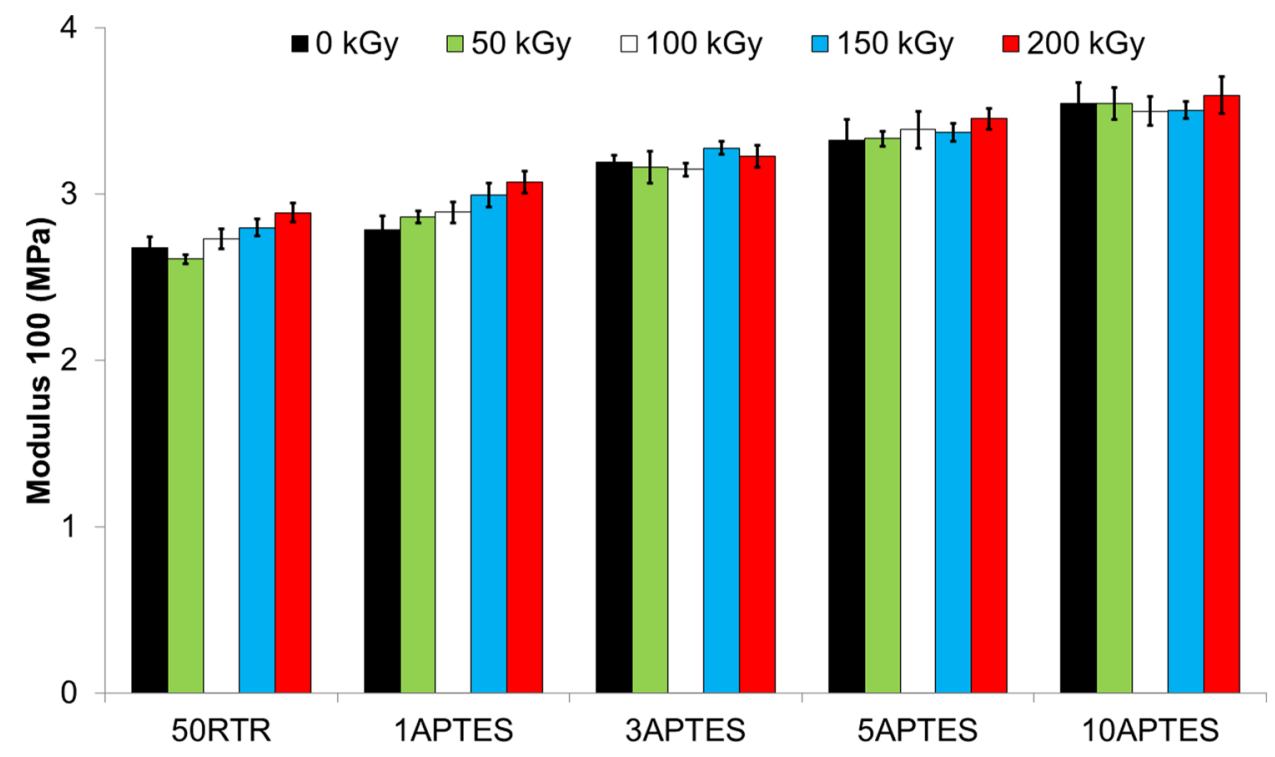

to the control blend, 50RTR. Such observation can be accounted to increased reclamation of RTR particles and enhanced adhesion between RTR and EVA matrix. Tear strength beyond $5 \mathrm{wt} \%$ APTES loading showed a plateau suggesting that the compatibility of 50RTR/5APTES has reached an adequacy enabling maximum tear strength. In Han and Han [26]'s previous work, the increment in intrinsic strength was reported due to enhanced energy dissipation and/or deviation of tear path which contribute to the increases in tear energy of filled system. Tear strength of the APTES containing blends increased via efficiently arrested or deflected crack which initiates and propagates through the bulk due to improved dispersion of smaller RTR particles. The dispersion of RTR at $5 \mathrm{wt} \%$ APTES loading might have been the optimum, resulting in a plateau of tear strength thereon. Irradiation only improved the tear strength of $1 \mathrm{wt} \%$ APTES blend with minimal or no improvement noted at higher APTES loading.

In Fig. 10, at $0 \mathrm{kGy}$, APTES containing blends showed an increase in hardness values up to $5 \mathrm{wt} \%$ APTES loading, with saturation thereon. Microstructural change of EVA following the interaction with APTES could have caused this observation. All APTES containing blends upon irradiation showed improved hardness by a meagre 1 to $3 \%$.
Fig. 9 Effect of irradiation dose and APTES loading on tear strength of 50RTR and APTES containing blends

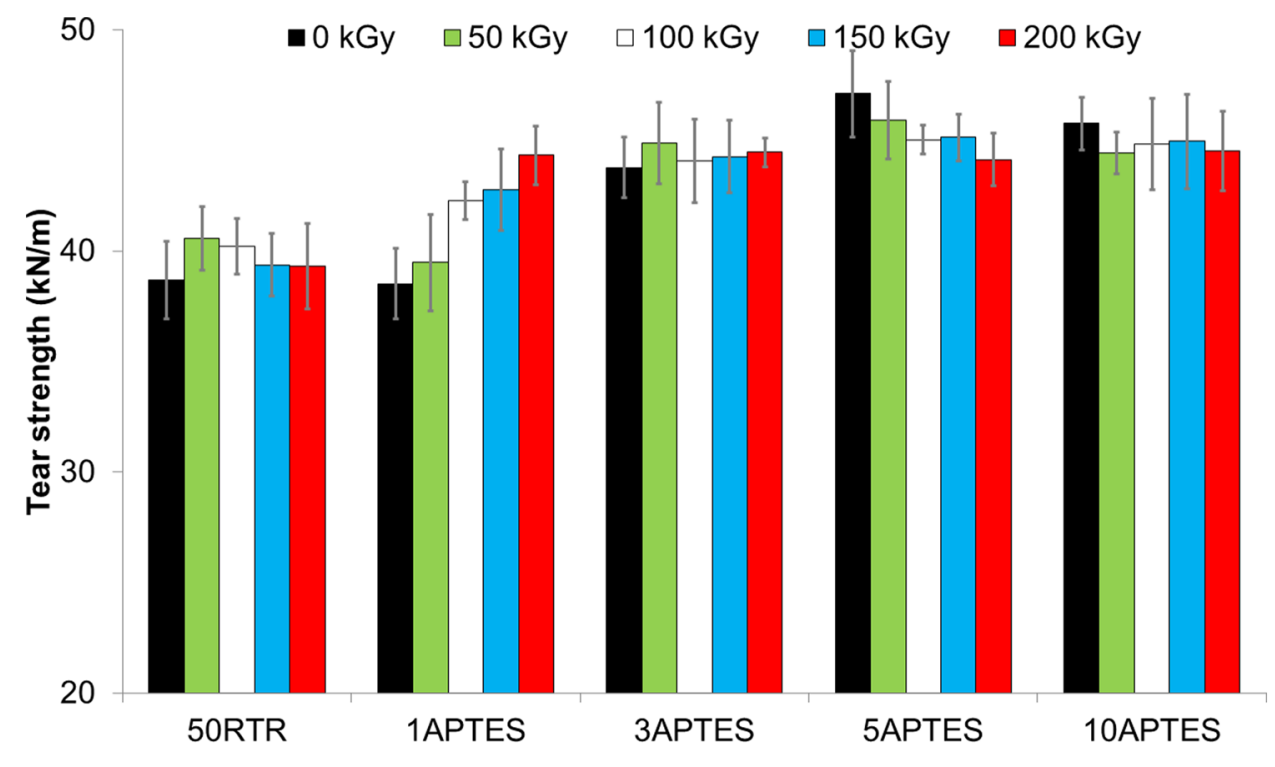


Fig. 10 Effect of irradiation dose and APTES loading on hardness of 50RTR and APTES containing blends

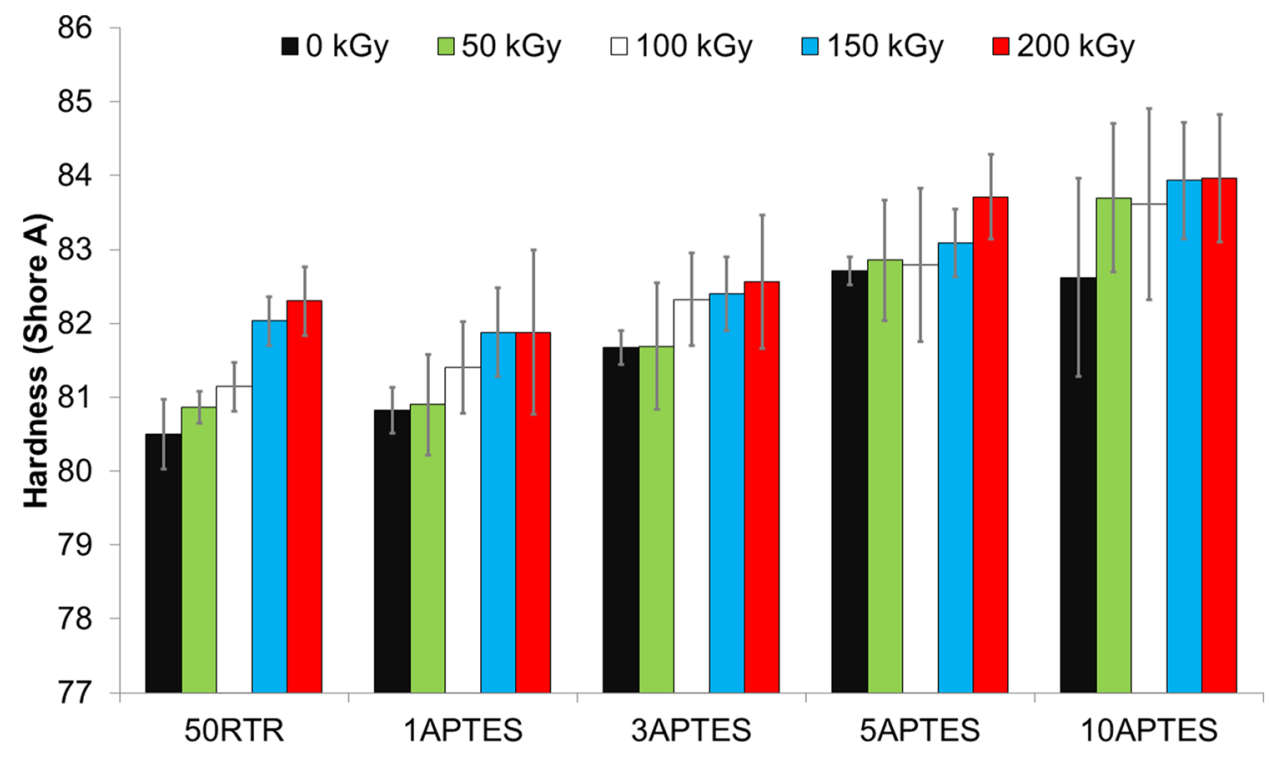

\section{Chemical mechanism of reclaiming and compatibilization}

In this study, we have used APTES, which contains a silane atom connected to a propyl spacer with the primary amine as the organofuntional group and three ethoxy groups. Figure 11a represents a readily happening hydrolysis process when moisture present in the atmosphere reacts with APTES. In this process, more reactive silanols groups are produced from hydrolysis of ethoxysilanes [27]. Subsequent to formation of silanols, polysiloxane network structure are formed from self-condensation of silanols $[28,29]$.

The combination of mechanical shearing and chemical aid is preferred to reclaim crosslinked rubber as the resulting reclaimed rubber have superior properties in comparison to rubber reclaimed by mechanical shearing only.
Chemicals such as thiols, phenols and disulphides have the capability to scavenge the radicals formed during mechanical shearing in chemical aided method used for reclaiming vulcanized natural rubber [5, 20]. EPDM rubber are more commonly reclaimed by nucleophilic mechanism using amines. Amine is an excellent reclaiming agent, a strong nucleophile, specifically due to the ability to cleave cyclic octasulfur by primary and secondary amine [20]. Previous studies have shown amines capability of reclaiming rubber via a nucleophilic mechanism as shown in Fig. 12a. Waste tire rubber can also be reclaimed using APTES which contains the primary amine of the organofunctional group which cause decrement in molecular weight and gel content as discussed in earlier section. Carboxylic group are known to be present on degraded mass such as RTR [30]. Amine group of APTES reacting with these carboxylic groups can form a stable covalent bond as shown in
Fig. 11 Hydrolysis and self-condensation reaction in APTES a) Hydrolysis<smiles>CCO[Si](CN)(OCC)OCCCNCC(O)(O)O</smiles>

b) Self-condensation

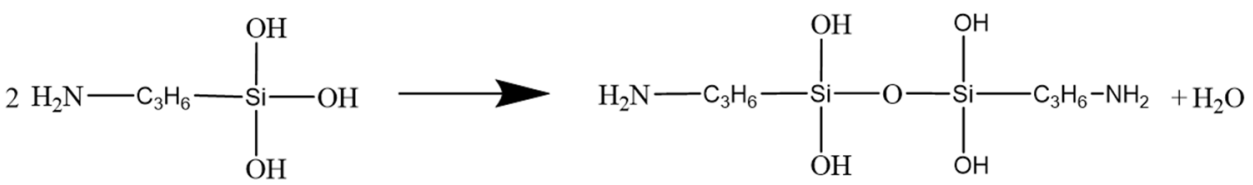


Fig. 12 Interaction between APTES and RTR a) Reclamation by nucleophilic reaction

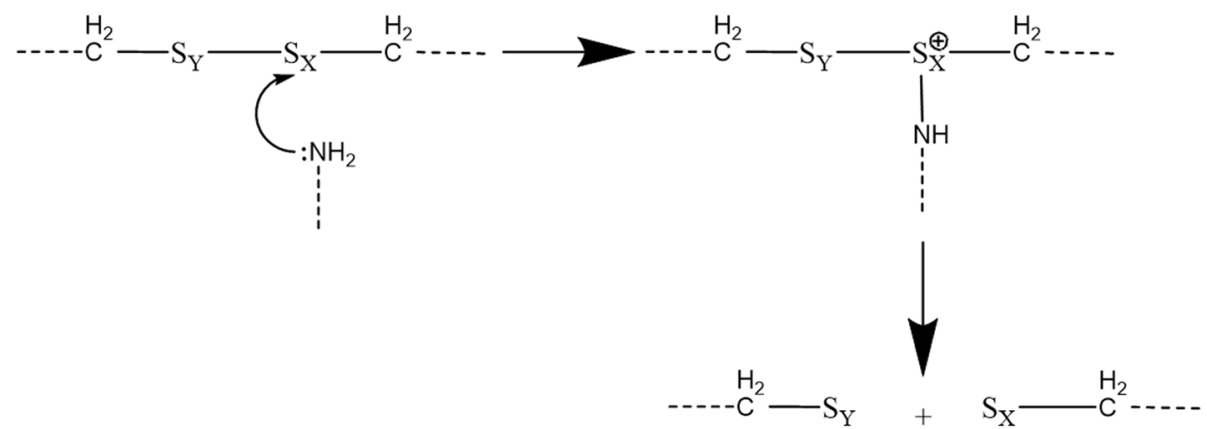

b) Interaction between carbonyl and amine group

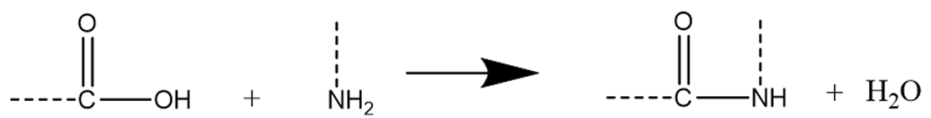

Fig. 12b [31, 32]. The $110^{\circ} \mathrm{C}$ processing temperature further aided this process.

the interaction between EVA and APTES. Amine group of APTES could interact with carboxylate ester of vinyl acetate group within EVA, thereby, reducing the vinyl acetate to alcohol as shown in Fig. 13a. The processing temperature
Addition of APTES altered the properties of EVA matrix causing the changes to the EVA microstructure following a) Interaction between carboxylate ester and amine APTES and EVA<smiles>[R]O[C@H]([O-])[C@@](C)([O])NI</smiles><smiles>[R]OC(O[R])[Si](O)(O)CN[C@H]([R6])CN</smiles>

c) Chemical grafting

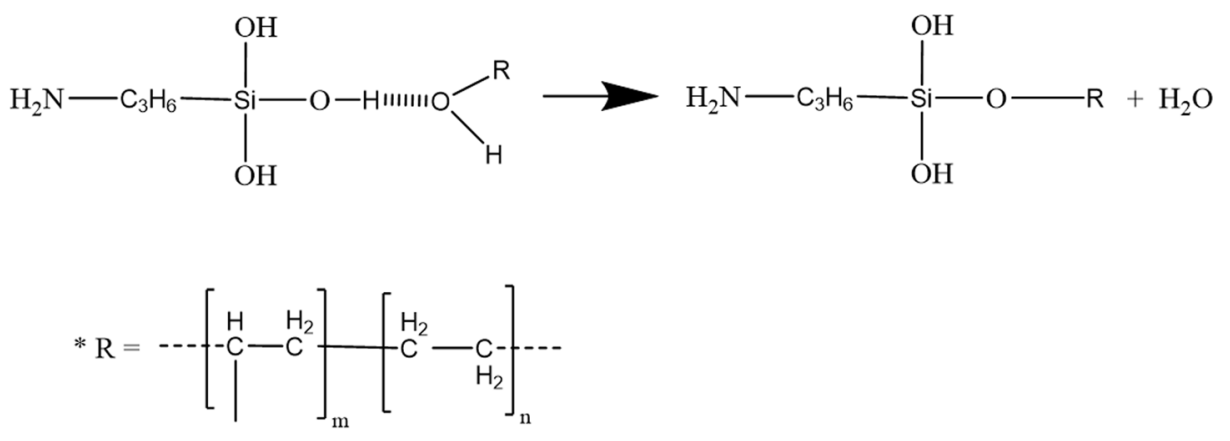


of $110{ }^{\circ} \mathrm{C}$ used in this study could easily facilitate the proposed reaction. EVA macromolecules with some hydroxyl $(-\mathrm{OH})$ groups within its backbone are produced from this reaction, which could further react with silanol groups of hydrolysed APTES and silanol groups of condensed APTES (polysiloxanes) [33]. These reactions are presented in Fig. 13b, c.

Reactive compatibilization of EVA and RTR with the use of APTES can aid strong interfacial adhesion in the blends. Covalent attachment between RTR and EVA via a combination of APTES reaction with RTR (Fig. 12b) and EVA (Fig. 13b, c), facilitate formation of a strong interphase. One of the reasons of improved mechanical properties in APTES compatibilized blends before irradiation is due to the formation of good interphase.

\section{Morphological study}

Figure 14a reveals the fracture surface of 50RTR blend with the clean and uncoated rubber particle (indicated by arrows). Empty voids present on the surface due to large particle pull out which indicates lack of adhesion between the EVA matrix and RTR particle.
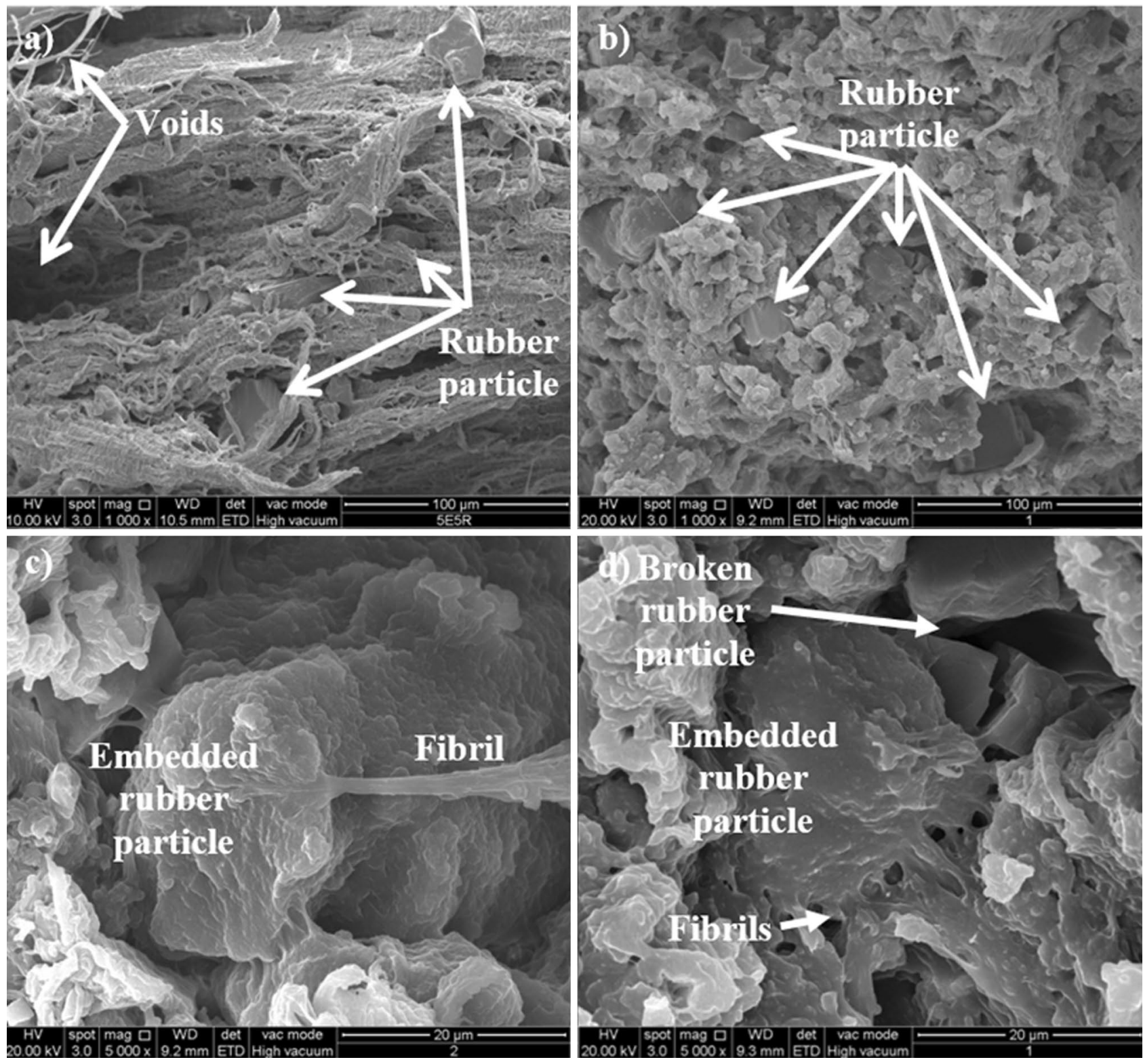

Fig. 14 SEM micrographs of $0 \mathrm{kGy}$ a) 50RTR and b,c,d) 3 wt \% APTES containing 50RTR blends with an overview at 1000x (a,b) and focused RTR particle in APTES containing blend at 5000x (c,d) magnification 
3 wt $\%$ APTES containing blends in Fig. 14b, showed dispersion of fully embedded RTR particles within EVA matrix. Smaller RTR particles were observed in APTES containing blend compared to 50RTR blend. Dispersion of the smaller rubber particle supports the claim that APTES functions as reclaiming agent in RTR. Softer rubber from reclaiming of RTR by APTES and the shearing during compounding makes it easier to break the rubber into smaller particle. This leads to EVA matrix with well dispersed smaller RTR particle.

RTR particles were fully embedded and interlocked together with EVA by fibril formation as shown in Fig. 14c, d. It is notable that the rubber particles also supported the applied stress which is evident from the broken or ruptured rubber particle [34, 35] as shown in Fig. 14d. This observation supports effective formation of interfacial adhesion between EVA and RTR in the presence of APTES allowing for enhanced tensile properties before irradiation. EVA matrix in APTES containing blends shows no indication or signs of fibrillation on the matrix surface in comparison to 50RTR blend. This supports the discussion in EB, whereby the EVA microstructure was expected to be altered due to interaction with APTES.
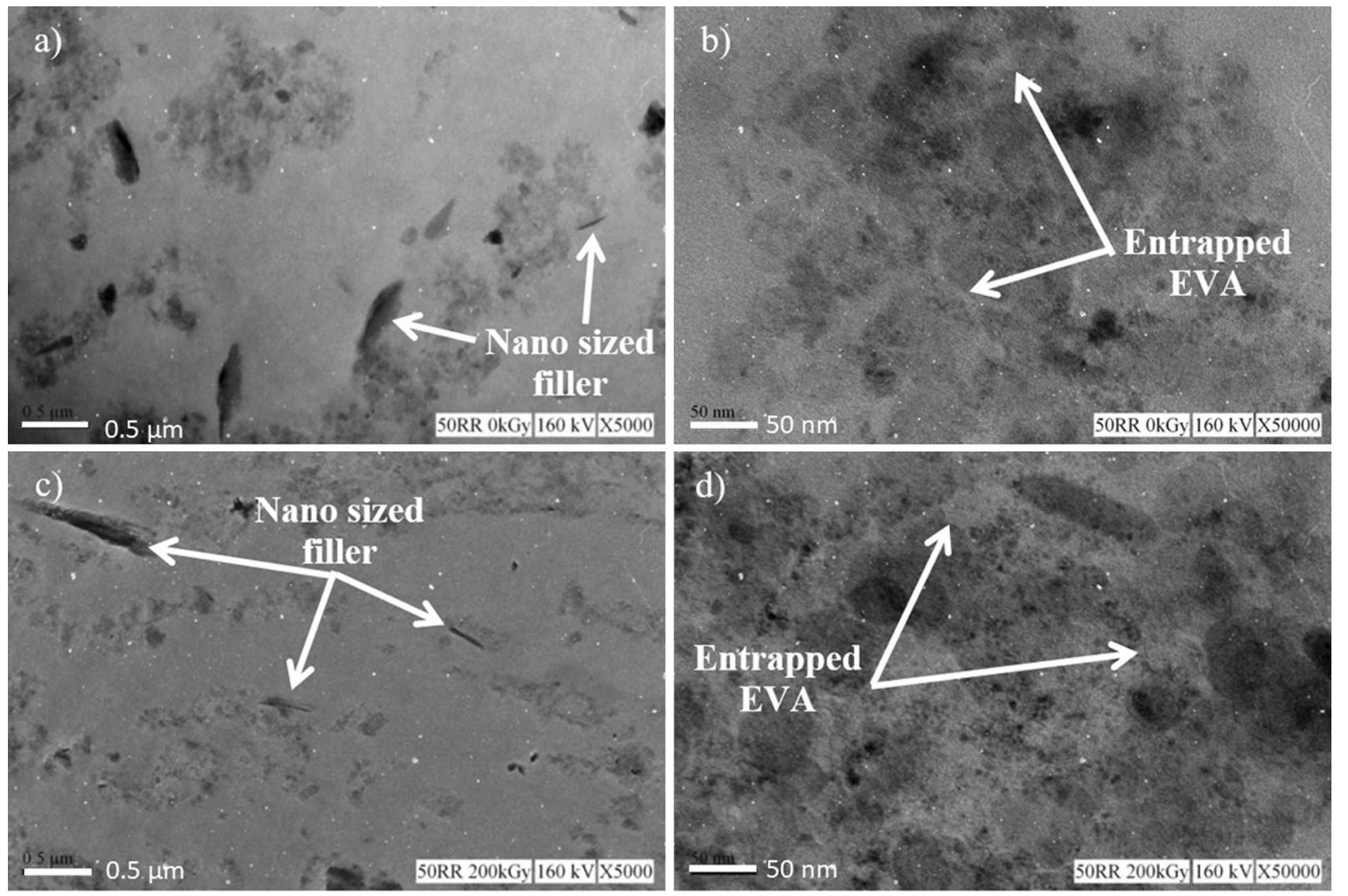

Fig. 15 TEM micrographs of 50RTR blends before irradiation at a) 5000X, b) 50000X and after $200 \mathrm{kGy}$ irradiation at c) $5000 \mathrm{X}$ and d) $50000 \mathrm{X}$ magnification 

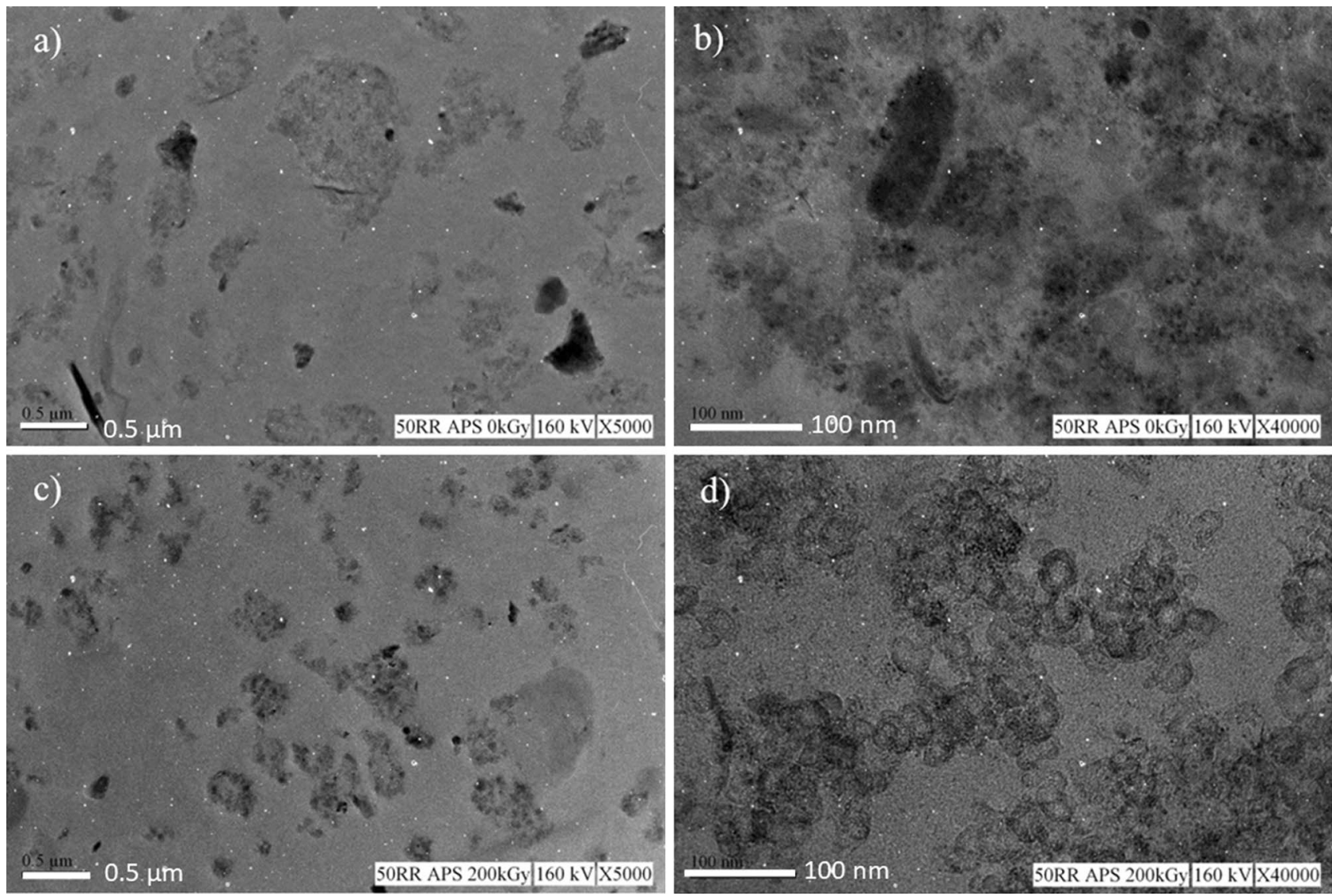

Fig. 16 TEM micrographs of $3 \mathrm{wt} \%$ APTES containing blends before irradiation at a) 5000X, b) 50000X and after $200 \mathrm{kGy}$ irradiation at c) $5000 \mathrm{X}$ and d) 50000X magnification

TEM micrographs of APTES containing 50RTR blends before and after irradiation are shown in Fig. 16. As per 50RTR blend, domains of RTR (darker grey shade) distributed in EVA matrix (lighter grey shade) was also observed in the APTES containing blends. At $0 \mathrm{kGy}$, RTR domain size in APTES containing blends are measured to be in between 0.3 to $1.0 \mu \mathrm{m}$, approximately $50 \%$ smaller compared to 50RTR blend. This observation proves the earlier claims of APTES being able to further reclaim RTR; allowing for smaller RTR domain sizes within EVA matrix. Reduced contrast between EVA matrix and RTR domain also suggest enhanced compatibility in APTES containing blends. At $200 \mathrm{kGy}$ irradiation dose, further reduction of the domain sizes of RTR to 0.1 to $0.5 \mu \mathrm{m}$ was noted. Similar to 50RTR, higher contrast was noted between RTR domains and EVA matrix in APTES containing blends upon irradiation. These observations indicate heterogeneity or distinct phase separation in APTES containing blends upon irradiation. This can be owed to enhancement of irradiation induced crosslinks formation in these samples.

Figures 16b, d show the difference in the RTR domain of APTES containing blends, before and after irradiation, respectively. Different grey colored patches within RTR domain before irradiation signifies the partially devulcanized state of the rubber. The darker grey indicates crosslinked rubber region while the lighter grey shades indicate the amorphous/free rubber chains. At $200 \mathrm{kGy}$, distinct changes to the patches of different grey shades with overlapping spherical shapes in different grey shades was observed. Similar observation was not noted in control, 50RTR blend. Therefore, this could be due to efficient crosslink formation in APTES containing blends.

\section{Calorimetric analysis}

DSC thermograms of 50RTR and APTES containing blends at before and after $200 \mathrm{kGy}$ irradiation doses are presented in Fig. 17. A distinct narrowing of melting and cooling peak was observed in compatibilized blends. Whereas irradiation caused shift of melting and cooling peaks toward lower temperature along with a reduction in the height of peak; especially prominent in APTES containing blend. To aid the discussion, Fig. 18 was charted using raw data collected from DSC analysis. 
Fig. 17 Influence of irradiation dosage on DSC thermograms of 50RTR and APTES containing 50RTR blends

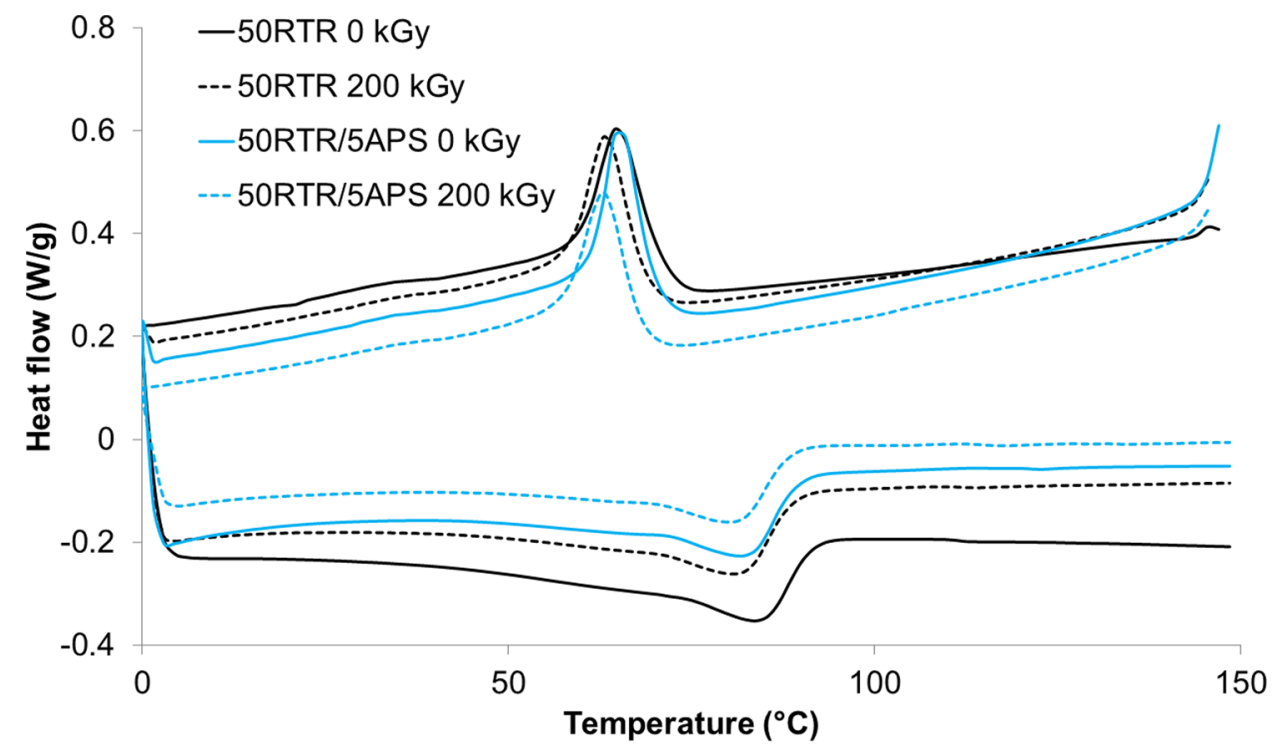

Figure 18a shows the crystallization temperature $\left(\mathrm{T}_{\mathrm{c}}\right)$ of APTES compatibilized blends at $0 \mathrm{kGy}$ increasing only minutely as compared to 50RTR blend. 50RTR and APTES compatibilized blends recorded $\mathrm{T}_{\mathrm{c}}$ of 65.0 and $65.5{ }^{\circ} \mathrm{C}$, respectively. Adhesion between RTR and EVA increased as compatibilization effectively reduced the interfacial tension. Hence, the nucleation effect rendered by RTR is enhanced, requiring higher amount of energy to form crystal [14]. Similar to 50RTR blend, a decrease in the $T_{c}$ of APTES containing blends was noted with increase in irradiation dose. The net amount of EVA chains involved in chain rearrangement to form crystals decreases with irradiation induced crosslinks in the blends, leading to a drop in $\mathrm{T}_{\mathrm{c}}$ with rise in irradiation dose.

APTES containing blends has melting temperature $\left(\mathrm{T}_{\mathrm{m}}\right)$ lower than control, 50RTR blend which suggest imperfect and/or lesser amount of crystals are formed compared to 50RTR blend [39]. At $0 \mathrm{kGy}, 50 \mathrm{RTR}$ and 50RTR/5APTES blends showed $\mathrm{T}_{\mathrm{m}}$ of 84.2 and $82.8{ }^{\circ} \mathrm{C}$, respectively. This observation supports good interfacial interaction [40] between EVA and RTR which hinders the growth of EVA crystals. Increasing irradiation dose also recorded decreased $\mathrm{T}_{\mathrm{m}}$ of APTES containing blends. However, at $200 \mathrm{kGy}$ the extent of decrease in $\mathrm{T}_{\mathrm{m}}$ of APTES containing blends $(1.4 \%)$ was lesser compared to control, 50RTR blend (3.0\%). Before irradiation, the compatibilization leads to smaller and/or lower amount of crystals formed in the blends while, in irradiated 50RTR blend, the higher possibility of EVA chain movements (due to lesser crosslinking efficiency) lead to increased crystal formation as compared to the compatibilized blends.

Figures 18c, d show the effect of irradiation dosage on crystallinity and heat of fusion of the compatibilized blends, respectively. Intriguingly, at $0 \mathrm{kGy}$, APTES containing blends recorded higher crystallinity and heat of fusion compared to 50RTR blend. Compatibilized PP/NBR blends [41] and PA6/SEBS blends [42] reported similar observation. Increased crystallinity of APTES containing blends are aligned with improvement in tear and tensile strength of the blends. Improved interfacial adhesion enhanced nucleating capability of the blends, causing in improved crystallinity and heat of fusion of the blends [43]. Improved crystallinity of APTES containing blend could also be caused by microstructural changes in EVA.

Increase in irradiation dose caused a drop in crystallinity and heat of fusion of the APTES containing blends. This is quite conflicting to control, 50RTR, which showed higher crystallinity and heat of fusion in irradiated blends compared to un-irradiated 50RTR blend. In 50RTR blend, higher flexibility for EVA chain rearrangements and recrystallization was possible due to redistribution of RTR and lower crosslinking efficiency. Gel content analysis also confirmed the increased crosslinking efficiency in APTES containing blends. Upon irradiation, more crosslinks were formed in APTES containing blends compared to 50RTR blends. Hence, this lead to lower degree of rearrangement in EVA chain to enable crystals formation in APTES containing blends causing greater decline in crystallinity upon irradiation [39].

\section{Thermal degradation properties}

The thermal degradation of 50RTR and APTES compatibilized blends were studied using thermogravimetry analysis. The weight loss curve with respect to temperature is presented in Fig. 19. All samples underwent two-step 
a)

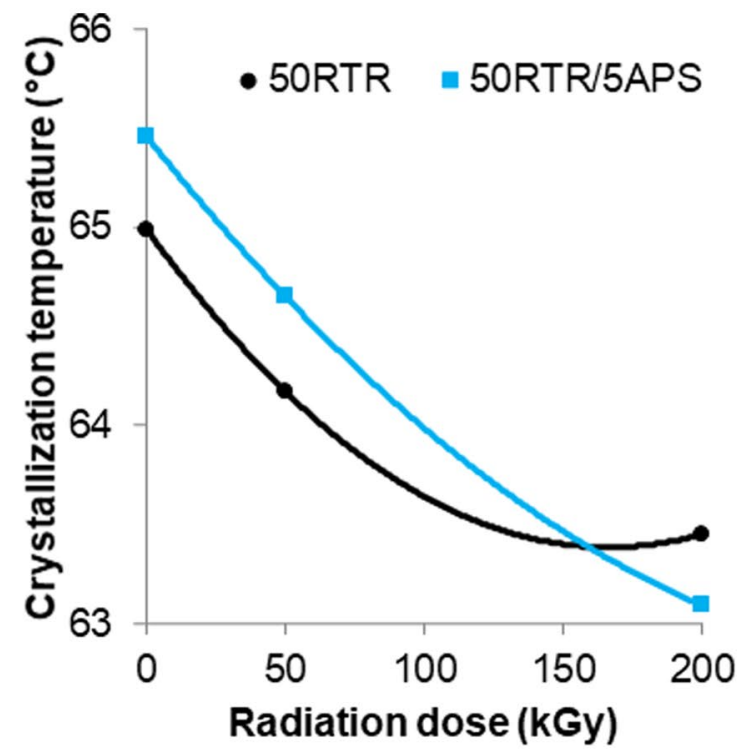

c)

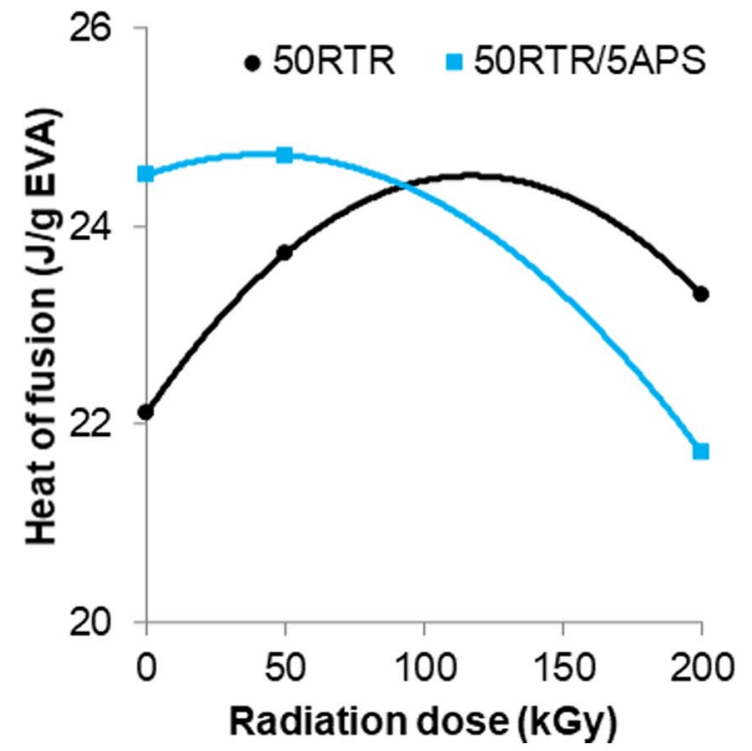

b)

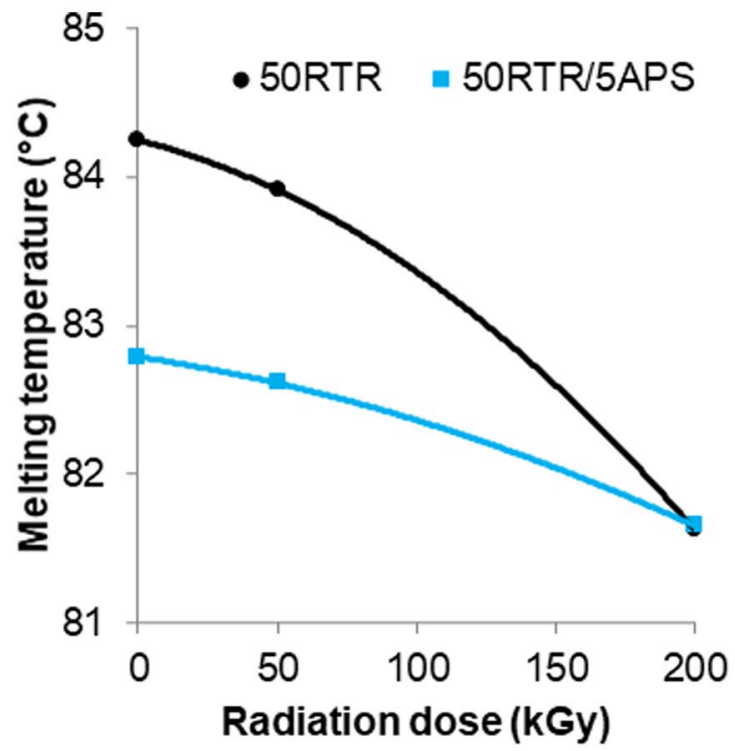

d)

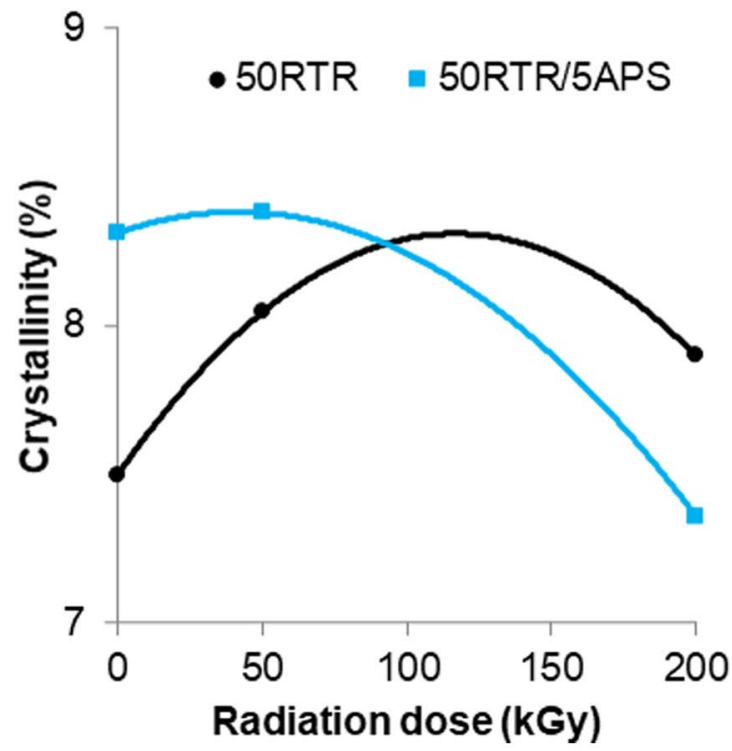

Fig. 18 Influence of irradiation dosage on a) Crystallization temperature, b) Melting temperature, c) Heat of fusion and d) Crystallinity of 50RTR and APTES containing blends

degradation process. Table 6 list the temperature corresponding to specific and maximum weight losses. The maximum temperature for first and second degradation steps were recorded around $360{ }^{\circ} \mathrm{C}$ and $475{ }^{\circ} \mathrm{C}$, respectively. As reported in previous communication [25], the first degradation step corresponds to the intensive loss of vinyl acetate (component from EVA) and depolymerization of natural rubber (component from RTR). Whereas the second degradation step corresponds to the intensive depolymerization of polyethylene chain (component from EVA) and butadiene rubber (component from RTR). The weight loss observed below $300{ }^{\circ} \mathrm{C}$ is associated to loss of volatile organic compounds such as additives, oils and oligomers [44].
Non-irradiated APTES compatibilized blends showed slightly enhanced thermal stability of about 3 to $7^{\circ} \mathrm{C}$ up till the onset of second degradation step. Use of APTES facilitated the dispersion of RTR in smaller domain sizes within EVA matrix increasing effective interfacial area. Additionally, the APTES compatibilization mechanism also indicated vinyl acetate group responsible for the first degradation step might have been consumed during the interphase formation. Both these factors contributed to the enhanced thermal stability observed in APTES compatibilized blends. Contrarily, the second degradation step was not affected by the compatibilization. This finding suggests the compatibilization had no significant effect on the polyethylene backbone of EVA and butadiene rubber component of RTR. 
Fig. 19 Influence of compatibilization and irradiation on 50RTR blends thermal stability

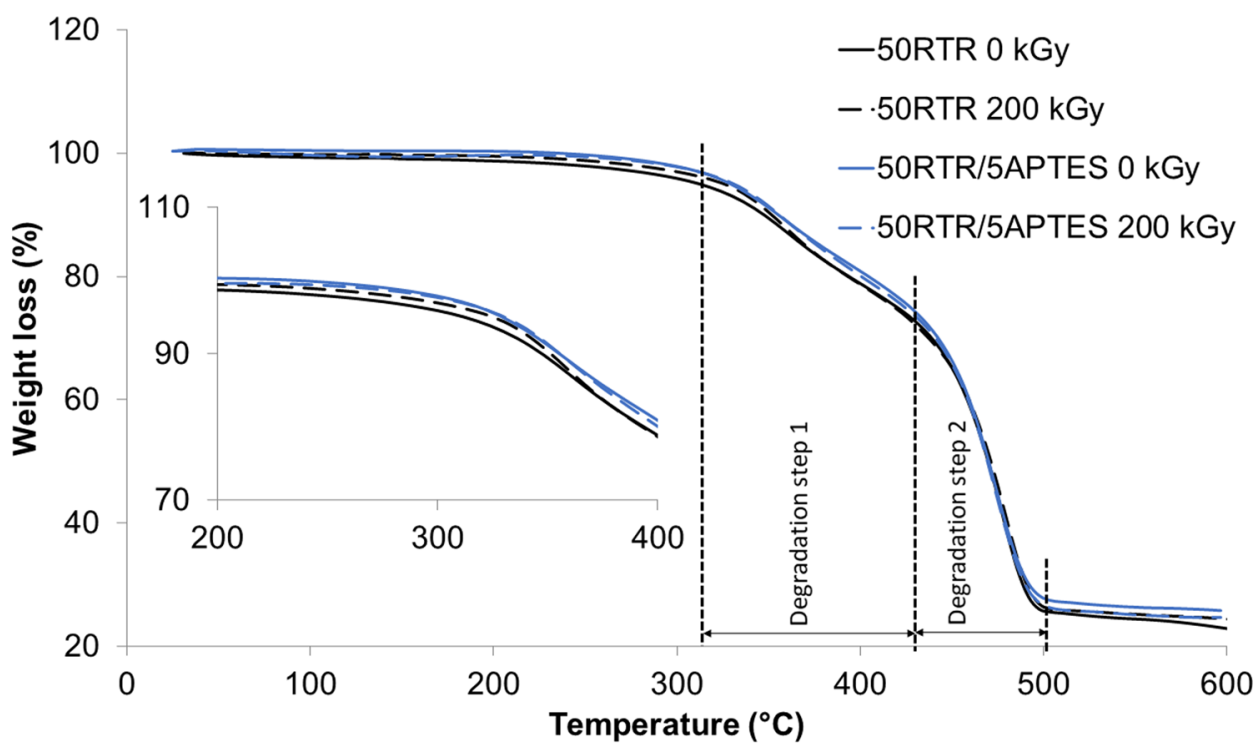

\begin{tabular}{|c|c|c|c|c|c|c|c|c|}
\hline \multirow[t]{2}{*}{ Sample designation } & \multirow{2}{*}{$\begin{array}{l}\text { Radiation } \\
\text { dose (kGy) }\end{array}$} & \multicolumn{6}{|c|}{ Degradation temperature $\left({ }^{\circ} \mathrm{C}\right)$} & \multirow{2}{*}{$\begin{array}{l}\text { Residual } \\
\text { wt }(\%)\end{array}$} \\
\hline & & $\mathbf{T}_{\mathbf{5} \%}$ & $\mathbf{T}_{10 \%}$ & $\mathbf{T}_{\mathbf{2 5} \%}$ & $\mathbf{T}_{\mathbf{5 0} \%}$ & $\mathbf{T}_{\max 1}$ & $\mathbf{T}_{\max 2}$ & \\
\hline 50RTR & 0 & 312.0 & 348.2 & 419.9 & 471.5 & 360.3 & 479.4 & 23.0 \\
\hline 5APTES & 0 & 328.3 & 351.7 & 427.5 & 468.3 & 375.5 & 474.2 & 26.8 \\
\hline 50RTR & 200 & 324.2 & 348.4 & 419.7 & 470.3 & 360.1 & 479.6 & 24.3 \\
\hline 5АPTES & 200 & 324.0 & 351.7 & 421.7 & 468.3 & 373.3 & 474.2 & 24.7 \\
\hline
\end{tabular}

Table 6 Temperatures corresponding to specific weight loss and residual weight of 50RTR and APTES compatibilized blends, before and after irradiation
Irradiation enhanced thermal stability of 50RTR blend by about $10 \%$ up to $350{ }^{\circ} \mathrm{C}$. However, irradiation had no influence on the thermal stability of APTES compatibilized 50RTR blend. This was an interesting finding because in both cases, the RTR domain sizes decreased in irradiated samples. Gel content recorded at $200 \mathrm{kGy}$ for both 50RTR and 50RTR/5APTES blends was $61.5 \%$ and $71.6 \%$, respectively, indicating formation of crosslinks. Indeed, there is possibility for a complex molecular change happening in an irradiated sample that influences its thermal stabilities.

\section{Conclusion}

Results revealed that APTES play dual role in RTR/EVA blends: as compatibilizer and as reclaiming agent. Compatibilizing and reclaiming lead to improved mechanical properties in APTES compatibilized 50RTR blend. $5 \mathrm{wt} \%$ APTES was found to be the optimal loading for the compatibilized blends. Crystallinity of 5wt\% APTES compatibilized blends was higher in un-irradiated and low irradiation dose, resulting in higher mechanical properties in the blends. Use of APTES has also ensured improved crosslinking efficiency in electron beam irradiated blends. However, interaction between EVA and APTES resulted in decreased ductility in the compatibilized blends.

Supplementary Information The online version contains supplementary material available at https://doi.org/10.1007/s10965-021-02748-y.

\section{Declarations}

Conflict of interest This study was funded by Ministry of Higher Education, Malaysia via Fundamental Research Grant Scheme (Ref: FRGS/1/2020/TK0/HWUM/03/1). The authors declare that they have no conflict of interest.

Open Access This article is licensed under a Creative Commons Attribution 4.0 International License, which permits use, sharing, adaptation, distribution and reproduction in any medium or format, as long as you give appropriate credit to the original author(s) and the source, provide a link to the Creative Commons licence, and indicate if changes were made. The images or other third party material in this article are included in the article's Creative Commons licence, unless indicated otherwise in a credit line to the material. If material is not included in the article's Creative Commons licence and your intended use is not permitted by statutory regulation or exceeds the permitted use, you will need to obtain permission directly from the copyright holder. To view a copy of this licence, visit http://creativecommons.org/licenses/by/4.0/. 


\section{References}

1. Rodgers B, Waddell W (2011) in Mark JE, Erman B, Eirich FR (eds)Science and Technology of Rubber, 3 edn. Elsevier Academic Press, United State of America

2. Karger-Kocsis J, Mészáros L, Bárány T (2013) J Mater Sci 48:1. https://doi.org/10.1007/s10853-012-6564-2

3. Shulman VL (2011) in Trevor L, Daniel V (eds)WasteAcademic Press, Boston

4. Sienkiewicz M, Kucinska-Lipka J, Janik H, Balas A (2012) Waste Manage 32:1742. https://doi.org/10.1016/j.wasman.2012.05.010

5. Adhikari B, De D, Maiti S (2000) Prog Polym Sci 25:909. https:// doi.org/10.1016/S0079-6700(00)00020-4

6. Saiwari S, Yusoh B, Thitithammawong A (2019) J Polym Environ 27:1141. https://doi.org/10.1007/s10924-019-01413-2

7. Ramarad S, Khalid M, Ratnam CT, Chuah AL, Rashmi W (2015) Prog Mater Sci 72:100. https://doi.org/10.1016/j.pmatsci.2015.02.004

8. Karger-Kocsis J (2013) eXRESS Polymer Letters 7: 406. https:// doi.org/10.3144/expresspolymlett.2013.37

9. Khalil AM, El-Nemr KF, Hassan ML (2019) J Polym Res 26:249. https://doi.org/10.1007/s10965-019-1914-2

10. Danielli Bastos de Sousa F, Scuracchio CH, Hu G-H, Hoppe S (2016) Journal of Applied Polymer Science 133. https://doi.org/ 10.1002/app.43503

11. Jiang C, Zhang Y, Ma L, Zhou L, He H (2018) Mater Chem Phys 220:161. https://doi.org/10.1016/j.matchemphys.2018.08.040

12. Sripornsawat B, Saiwari S, Nakason C (2018) Waste Manage 79:638. https://doi.org/10.1016/j.wasman.2018.08.038

13. Sripornsawat B, Saiwari S, Pichaiyut S, Nakason C (2016) Eur Polymer J 85:279. https://doi.org/10.1016/j.eurpolymj.2016.10.031

14. Valentini F, Dorigato A, Pegoretti A (2020) J Polym Environ 28:1737. https://doi.org/10.1007/s10924-020-01717-8

15. Makuuchi K, Cheng S (2012) Radiation Processing of Polymer Materials and its Industrial Applications John Wiley \& Sons, Inc.,

16. Sonnier R, Leroy E, Clerc L, Bergeret A, Lopez-Cuesta JM (2007) Polym Testing 26:274. https://doi.org/10.1016/j.polymertesting. 2006.10.011

17. Anis Sakinah ZA, Ratnam CT, Luqman Chuah A, Yaw TCS (2011) J Elastomers Plast 43: 239. https://doi.org/10.1177/ 0095244311398629

18. Song Y, Xu C, Zheng Q (2014) Soft Matter 10:2685. https://doi. org/10.1039/c3sm52856a

19. Ramarad S, Ratnam CT, Khalid M, Chuah AL (2015) Journal of Applied Polymer Science 132: n/a.https://doi.org/10.1002/app.41649

20. Myhre M, Saiwari S, Dierkes W, Noordermeer JWM (2012) Rubber Chem Technol 85:408. https://doi.org/10.5254/rct.12.87973

21. Movahed SO, Ansarifar A, Zohuri G, Ghaneie N, Kermany Y (2016) J Elastomers Plast 48:122. https://doi.org/10.1177/ 0095244314557975

22. Ratnam C, Zaman K (1999) Polym Degrad Stab 65:481. https:// doi.org/10.1016/S0141-3910(99)00039-7
23. Tadiello L, D’Arienzo M, Di Credico B et al (2015). Soft Matter. https://doi.org/10.1039/c5sm00536a

24. Youssef HA (2009) React Funct Polym 69:623. https://doi.org/10. 1016/j.reactfunctpolym.2009.04.014

25. Ramarad S, Ratnam CT, Khalid M, Chuah AL (2015) Journal of Applied Polymer Science 132.https://doi.org/10.1002/app.41649

26. Han S-C, Han M-H (2002) J Appl Polym Sci 85:2491. https://doi. org/10.1002/app.10575

27. Zhang MM, Yan HX, Gong C, Li TT (2014) eXRESS Polymer Letters 8: 413. https://doi.org/10.3144/expresspolymlett.2014.45

28. Xie Y, Hill CAS, Xiao Z, Militz H, Mai C (2010) Compos A Appl Sci Manuf 41:806. https://doi.org/10.1016/j.compositesa.2010.03.005

29. Aviles F, Cauich-Rodriguez JV, Rodriguez-Gonzales JA, May-Pat A (2011) eXRESS Polymer Letters 5: 766.https://doi.org/10.3144/ expresspolymlett.2011.75

30. Başboğa İH, Atar İ, Karakuş K, Mengeloğlu F (2020) J Polym Environ 28:1776. https://doi.org/10.1007/s10924-020-01726-7

31. Demjén Z, Pukánszky B, Nagy J Jr (1999) Polymer 40:1763. https://doi.org/10.1016/S0032-3861(98)00396-6

32. Pukánszky B, Demjén Z (1999) Macromol Symp 139:93. https:// doi.org/10.1002/masy.19991390111

33. Pei Q-X, Sorkin V, Liu P et al (2021) J Polym Res 28:29. https:// doi.org/10.1007/s10965-020-02371-3

34. Dasdemir M, Maze B, Anantharamaiah N, Pourdeyhimi B (2015) Eur Polymer J 63:194. https://doi.org/10.1016/j.eurpolymj.2014.12.019

35. l'Abee RMA, van Duin M, Spoelstra AB, Goossens JGP (2010) Soft Matter 6: 1758. https://doi.org/10.1039/b913458a

36. Munusamy Y, Ismail H, Ratnam CT (2012) J Reinf Plast Compos 31:946. https://doi.org/10.1177/0731684412451938

37. Li Z, Nambiar S, Zheng W, Yeow JTW (2013) Mater Lett 108:79. https://doi.org/10.1016/j.matlet.2013.06.030

38. Jung C-H, Lee D-H, Hwang I-T et al (2013) J Nucl Mater 438:41. https://doi.org/10.1016/j.jnucmat.2013.03.023

39. Tang Z, Wang M, Tian F, Xu L, Wu G (2014) Eur Polymer J 59:156. https://doi.org/10.1016/j.eurpolymj.2014.07.013

40. Song P, Li S, Wang S (2017) Polym Degrad Stab 143:85. https:// doi.org/10.1016/j.polymdegradstab.2017.06.020

41. Tian M, Han J, Zou H et al (2011) J Polym Res 19:9745. https:// doi.org/10.1007/s10965-011-9745-9

42. Hemlata, Maiti SN (2012) J Polym Res 19: 9926. https://doi.org/ 10.1007/s10965-012-9926-1

43. Ramarad S, Ratnam CT, Khalid M, Chuah AL, Hanson S (2017) Radiat Phys Chem 130:362. https://doi.org/10.1016/j. radphyschem.2016.09.023

44. Barbosa R, Ambrósio JD (2019) J Polym Res 26:160. https://doi. org/10.1007/s10965-019-1820-7

Publisher's Note Springer Nature remains neutral with regard to jurisdictional claims in published maps and institutional affiliations.

\section{Authors and Affiliations}

\section{Suganti Ramarad' ${ }^{1}$ (1) Chantara Thevy Ratnam ${ }^{2} \cdot$ Yamuna Munusamy $^{3} \cdot$ Nor Azura Abdul Rahim $^{4}$. Mathialagan Muniyadi ${ }^{3}$}

\author{
Chantara Thevy Ratnam \\ Chantara@nuclearmalaysia.gov.my \\ Yamuna Munusamy \\ yamunam@utar.edu.my
}

\author{
Nor Azura Abdul Rahim \\ norazura@unimap.edu.my \\ Mathialagan Muniyadi \\ mathialagan@utar.edu.my
}


1 School Engineering and Physical Sciences, Heriot-Watt University Malaysia, Putrajaya, 1, Jalan Venna P5/2, Precinct 5, 62200, Malaysia

2 Radiation Processing Technology Division, Malaysia Nuclear Agency (Nuclear Malaysia), Bangi 43000 Kajang, Malaysia

3 Department of Petrochemical Engineering, Faculty of Engineering and Green Technology, Universiti
Tunku Abdul Rahman, Jalan Universiti, Bandar Barat, Perak 31900 Kampar, Malaysia

4 Faculty of Chemical Engineering Technology, Universiti Malaysia Perlis (UniMAP), Perlis, Pusat Pengajian Jejawi 2, 02600 Arau, Malaysia 